\title{
¿Por qué lo llaman icono cuando quieren decir diagrama? Cimientos para una apologética exponencial de Charles Sanders Peirce en la teoría del cómic
}

\author{
Óscar García López
}

Óscar García López es licenciado en Teoría de la Literatura y Literatura Comparada por la Universidad Complutense de Madrid, donde se dedica a la investigación principalmente en dos ámbitos: la narrativa serial contemporánea y el cómic. Ha publicado varios artículos en las revistas digitales Tebeosfera y CuCo, Cuadernos de Cómic, ha coordinado y contribuido al libro de ensayos Watchmen: Radiografías de una explosion (Modernito Books, 2013) y participado en los libros sobre series de televisión Los Héroes están muertos (Dolmen, 2014) y Yo soy más de series (Esdrújula, 2015).

Fecha de recepción: 29 de mayo de 2016

Fecha de aceptación definitiva: 6 de noviembre de 2016 


\title{
Resumen
}

El concepto de diagrama, según fue considerado por C. S. Peirce, se propone en este texto como una categoría de interés fundamental en el acercamiento semiótico a la teoría del cómic. Esa importancia radicaría en su papel clave en el proceso cognitivo de recepción de cualquier imagen, desde su impresión inicial a una interpretación posterior más elaborada. La primera mirada de un ser humano a otro, esa percepción primigenia del recién nacido, servirá de ejemplo recurrente para ilustrar la argumentación, y permitirá abrir el campo de aplicación de la categoría de diagrama a otras consideraciones.

Palabras clave: C. S. Peirce, semiótica, diagrama, razonamiento diagramático.

\begin{abstract}
The concept of diagram, as was considered by C. S. Peirce, is proposed in this text as a category of fundamental interest in the semiotic approach to Comic Theory. That importance lies in its key role in the cognitive process of reception of any image, from an initial impression to a later and more elaborate interpretation. The first time a human being looks to another, that primal perception of the newborn, will serve as a recurring example to illustrate the argumentation, and will open the scope of the category of diagram to other considerations.
\end{abstract}

Keywords: C. S. Peirce, semiotics, diagram, diagrammatic thinking.

\section{Cita bibliográfica}

García López, Ó. «¿Por qué lo llaman icono cuando quieren decir diagrama? Cimientos para una apologética exponencial de Charles Sanders Peirce en la teoría del cómic», en CuCo, Cuadernos de cómic, n.o 7 (2016), pp. 35-65. 
Remember it is by icons only that we really reason, and abstract statements are valueless in reasoning except so far as they aid us to construct diagrams. ${ }^{1}$

Charles S. Peirce, Collected Papers 4.127²

[...] when I was researching Brought to Light, I found out that the Pentagon had done tests to see what was the means by which information could be most easily taken in and could be most easily retained. They'd tried straight text. They'd tried text with photographs. They'd tried illustrations with captions, photographs with captions, and they'd tried comics. Comics were best. ${ }^{3}$

Alan Moore entrevistado por Daniel Whiston ${ }^{4}$

1 «Recordad que es solo mediante iconos como procede nuestro razonamiento, y las afirmaciones abstractas carecen de valor en este proceso excepto en la medida en que sirven de ayuda para elaborar diagramas.» Todas las traducciones que aparecen en nota al pie son propias.

${ }^{2}$ La notación que se emplea en las citas tomadas de los textos de Peirce sigue el procedimiento empleado habitualmente que toma como referencia los ocho volúmenes de la obra Collected Papers of Charles Sanders Peirce indicando con un primer dígito el volumen en el que se encuentra el fragmento y con los tres siguientes el párrafo correspondiente.

3 «[...] cuando estaba documentándome para Brought to Light averigüé que el Pentágono había realizado pruebas para comprobar de qué modo la información podía asimilarse y retenerse más fácilmente. Probaron con texto aislado. Con texto acompañado de fotografías. Con ilustraciones subtituladas, fotografías subtituladas y probaron el cómic. El cómic fue la mejor opción».

${ }^{4}$ Berlatsky, E. L. (ed.). Alan Moore: Conversations. Jackson, University Press of Mississipi, 2012, p. 134. 


\section{Introducción: La irresistible capacidad de reapropiación icónica del cómic}

La porosidad genérica y formal de la novela encontró uno de sus comentarios críticos más celebrados y repetidos en una frase casual de Pío Baroja. Abandonada en un texto menor, en esa cita afirmaba que la novela: «es un saco donde cabe todo». ${ }^{5}$ Desde Cervantes a David Foster Wallace, pasando por James Joyce, Thomas Mann o Virginia Woolf, dentro de un listado innumerable de autores, las muestras de esa incontenible capacidad de absorción frente a cualquier estructura o tipología textual alimentan y reafirman la casual (in)definición novelística de Baroja. En una de las obras teóricas fundamentales en el ámbito de la aproximación semiótica al cómic se puede sentir, al detenerse en otra cita, cierto grado de resonancia respecto a esas palabras previas:

An important aspect of modern comics is the mixture of imaginary drawings and documented drawings, fusing these two categories almost to the point where they become identical. [...] The usage desires that comics delete every trace of its double origin, that it conceal it behind a homogeneous execution: at once a production of the imagination and a recycling of icons from every provenance-in eminently variable proportions. ${ }^{6}$

Las frases de Thierry Groensteen podrían proyectarse sobre la de Baroja encontrando acomodo en una afirmación distinta pero similar, en un mashup de crítica narrativa, gráfica y literaria simultáneamente: la novela gráfica es un saco donde cabe todo lo icónico. Puede parecer que al declarar esto no se consigue otra cosa que reiterar una obviedad, pero al profundizar en sus implicaciones quizá sea posible reconocer un rasgo único que diferencia el medio radicalmente de la literatura y llegar también a vislumbrar una de las claves en la evolución de la poética actual y futura del cómic.

Porque ese potencial inagotable de reapropiación icónica es algo específico de la historieta que no encuentra contrapartida en los textos literarios construidos únicamente en base a

\footnotetext{
${ }^{5}$ Baroja, P. Obras Completas. Vol. xvi. Barcelona, Círculo de Lectores, 1997. La cita pertenece a la obra recopilatoria de textos varios titulada Páginas de autocrítica.

6 «Una cualidad destacable de los cómics modernos es la fusión de dibujos imaginarios con dibujos documentados, uniendo ambas categorías hasta el punto de resultar idénticas. [...] El uso fomenta que el cómic elimine cualquier prueba de este origen doble, que la oculte tras una ejecución homogénea: a la vez producto de la imaginación y reciclaje de iconos de cualquier procedencia - en proporciones evidentemente variables». Groensteen, T. The system of comics. Jackson, University Press of Mississipi, 2007, p. 58.
} 
un código lingüístico. ${ }^{7}$ En una novela se podrán intercalar fotografías, o acompañar el texto con ilustraciones, pero ese tipo de estrategias no permiten acceder directamente al nivel esencial de su discurso. Las frases que línea tras línea van componiendo la narración no toleran que una imagen sustituya a una palabra sin que las características de ese discurso se alteren radicalmente. Esta última posibilidad puede tomar forma en textos infantiles de carácter didáctico, destinados a facilitar el aprendizaje lector, donde la presencia de la imagen ofrece una referencia visual que las palabras, por su condición de símbolos convencionales sin relación con los objetos a que se refieren, no pueden emular. Pero dentro de un texto no podremos hallar otra cosa que no sean letras sin que el procedimiento de lectura cambie de tal modo que sea inevitable pensar que nos encontramos frente a algo modalmente distinto.

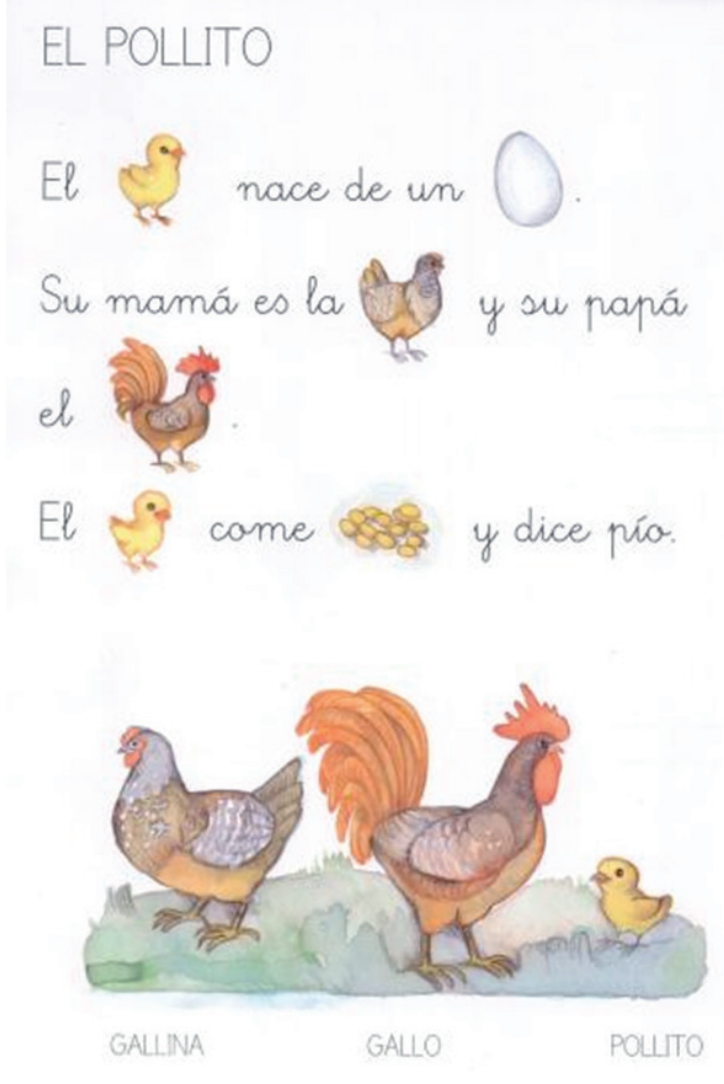

FIG. 1. Incorporación de imágenes en el discurso verbal.

Intentaremos en este texto investigar esa cualidad propia del cómic que le permite abrir sus páginas y viñetas a cualquier tipo de manifestación icónica o textual. Recuperaremos para ello algunas categorías semióticas caídas en desuso, rescatándolas de su injustificado olvido en un limbo teórico. Defenderemos la importancia de las contribuciones de aquel que las

7 Dentro del código lingüístico podemos encontrar palabras que poseen también un carácter icónico, como son las onomatopeyas, pero a lo que se alude aquí es a la imposibilidad de integrar imágenes en el discurso lingüístico. 
forjó y apelaremos a la merecida restitución de su figura y sus propuestas a la práctica actual del análisis semiótico del medio. Acudiremos a un ejemplo recurrente, regresando una y otra a vez a considerar esa mirada fundacional que se detiene por primera vez en el rostro de otro ser humano e intentaremos alcanzar el más allá de lo que vemos en sus rasgos. Y una vez desvelado ese enigma podremos utilizarlo como excusa para aventurar una hipótesis que podría suponer una vía de aproximación diferente a la teoría del cómic. Sin más...

\section{Enter Charles Sanders Peirce: un Nikola Tesla para la semiótica. El diagrama como ele- mento fundamental de la iconicidad}

La tradición semiológica europea ${ }^{8}$ encuentra en Ferdinand de Saussure su figura fundacional, su origen de coordenadas a partir del que se orientan la mayoría de las elaboraciones teóricas posteriores. En este ecosistema continental, donde florecieron estructuralismos y postestructuralismos, las aportaciones del filósofo norteamericano Charles Sanders Peirce al ámbito de la semiótica han quedado relegadas a un segundo plano. La única de sus contribuciones que mantiene cierta vigencia generalista, como concepto operativo, es esa versión simplificada de su taxonomía de los signos que en función de la relación con su objeto los divide en iconos — que se asemejan al objeto que representan-, índices — que establecen con su objeto una conexión real una relación de contigüidad- y símbolos - que establecen un vínculo con su objeto basado en la aceptación de una convención establecida, en el reconocimiento tácito por parte del intérprete del signo. ${ }^{9}$ La dificultad que conlleva su estudio, al no haber publicado Peirce ninguna obra completa sistematizada y hallarse repartidos sus textos en un inconmensurable corpus de artículos, anotaciones y cartas, puede esgrimirse como razón que ayude a entender este soslayamiento: investigar a Peirce es como acercarse a los manuscritos del Mar Muerto. Pero comprender no redunda en justificar: saber de la presencia de un obstáculo no debe presuponer el abandono de un camino a seguir. Porque una vez se pisa territorio peirceano no es fácil volver la mirada atrás y resistir a la fascinación que destilan algunas de sus ideas. Entre ellas el concepto de diagrama que presentaremos a continuación.

Es importante comenzar enfatizando dos aspectos claves en la consideración semiótica de cualquier signo. Primero, que las categorías propuestas por Peirce no constituyen clases

\footnotetext{
${ }^{8}$ La denominación «Semiología» se impuso en los estudios de este tipo efectuados en Europa siguiendo la estela de la disciplina lingüística (que resultaría una rama de la Semiología) inaugurada por Saussure. En Estados Unidos, siguiendo los pasos de Peirce, la preferencia terminológica se decantó por el término «Semiótica», que ha acabado imponiéndose en el uso general.

9 Volviendo a la representación de la FIG.1, a partir de la clasificación de los signos establecida por Peirce podríamos justificar el uso de iconos (imágenes de pollito, gallo y gallina) en el aprendizaje de la lectura debido a esa relación de analogía que establecen con su objeto, que facilita la interpretación del signo y lo hace aprehensible de manera más inmediata, mientras que la representación simbólica que entraña el uso de palabras implica un mayor grado de abstracción y complejidad interpretativa. La clasificación de los signos en iconos, índices y símbolos establece un orden jerárquico triádico que Peirce mantuvo como estructura de referencia a la hora de definir el resto de categorías en su extensa taxonomía semiótica, en la que siempre aplicaba criterios de «Firstness», «Secondness» $\mathrm{y}$ «Thirdness».
} 
cerradas, sino que un mismo signo puede pertenecer a distintas subclases siempre que se ajuste a las condiciones que definen a las mismas. No debemos pensar en signos que sean iconos, símbolos o índices, sino en signos que poseen funciones icónicas, indexicales o simbólicas en distinto grado. Y segundo, en la mayoría de los signos van a poder identificarse otros de menor orden que contribuyen a su composición general.

Teniendo esto en cuenta, en la clasificación de los signos en función de su modo de representación que edificó Peirce, los iconos resultaban divididos de nuevo en tres subcategorías o hipoiconos: la imagen, que representa cualidades simples de su objeto; el diagrama, que representa las relaciones entre las partes de su objeto mediante relaciones análogas entre sus partes, y la metáfora que representa a su objeto mediante una similitud con un tercero. Esta clasificación, como el resto de estructuras triádicas teorizadas por Peirce, además de establecer una relación jerárquica, posee un carácter inclusivo, de forma que cuando nos encontramos con un diagrama observamos que este incorpora algún tipo de imagen y del mismo modo las metáforas incluirán diagramas y, por lo tanto, también imágenes.

Según señala Stjernfelt, los diagramas juegan un papel fundamental en la iconicidad como categoría semiótica, ya que en el momento en que un icono es percibido como un todo compuesto de partes interrelacionadas, estamos operando sobre él de modo diagramático. Si por ejemplo nos acercamos al lienzo de un paisaje, en el momento en que dejamos de apreciar sus cualidades simples — colores, formas...- y pasamos a considerar las relaciones entre sus partes —entre fondo y primer plano, distancias entre objetos representados...estamos dando el salto desde una aproximación que lo trata semióticamente como una imagen a otra que lo estudia como diagrama. Resulta inevitable detenerse a apreciar un signo icónico sin realizar involuntariamente operaciones protodiagramáticas que nos revelen aspectos inherentes más allá de sus cualidades simples. Teniendo esto en cuenta, el empleo de un signo como imagen pura resultaría una experiencia semiótica límite y poco frecuente, una cognición primigenia, una mirada tan inocente como la que dirige el recién nacido por primera vez al rostro de su madre, una primera impresión que a posteriori sería elaborada accediendo a la condición diagramática de ese icono. Por otro lado, al reconocimiento de una metáfora le precedería un análisis diagramático, consciente o no, que reconociendo un esquema en un determinado fenómeno permitiría trasladarlo a la comprensión de otro. Por ejemplo, un árbol familiar presupone la traslación del diagrama de las ramas que se bifurcan en un árbol a las generaciones que se suceden en el tiempo dentro de una misma familia. ${ }^{10}$

\section{Pensando con iconos: diagramas para dummies}

La definición de icono ampliamente difundida, que se basa en la similitud entre signo y objeto, resultaría una simplificación conceptual que no hace justicia a la profundidad y riqueza de los desarrollos teóricos de Peirce. Frederick Stjernfelt ha reorientado su caracterización

${ }_{10}$ Stjernfelt, F. «Diagrams as Centerpiece of a Peircean Epistemology» en Transactions of the Charles $S$. Peirce Society, Vol. xxxvi, n. 3 (2000), pp. 360-361. 
apuntando hacia una definición con carácter operacional que se deduciría de la siguiente cita de Peirce:

For a great distinguishing property of the icon is that by the direct observation of it other truths concerning its object can be discovered than those which suffice to determine its construction $(2.279) .{ }^{11}$

La relación de similitud que servía de fundamento a la definición inicial se ve ampliada aquí con la consideración de ese potencial epistemológico que también incorpora el icono. Además de la representación analógica de ciertas cualidades de su objeto, la observación del icono y su manipulación permiten averiguar información adicional. En ese proceso de actuación sobre el icono inevitablemente se opera sobre él de forma diagramática, se consideran sus partes y las relaciones entre ellas y se extraen nuevas conclusiones. En el texto "The Algebra of Logic», en el marco de una discusión sobre la elaboración de silogismos, Peirce realizaba la siguiente afirmación, cargada de implicaciones generales aplicables a la categoría de icono y donde subraya su potencial operativo:

[...] All deductive reasoning, even simple syllogism, involves an element of observation; namely, deduction consists in constructing an icon or diagram the relations of whose parts shall present a complete analogy with those of the parts of the object of reasoning, of experimenting upon this image in the imagination, and of observing the result so as to discover unnoticed and hidden relations among the parts $(3.363) .{ }^{12}$

Para ilustrar estas ideas, Stjernfelt propone como ejemplo considerar el mapa del metro de Londres. Aparte de simplificar y reducir las trayectorias de las líneas de metro para que solo se orienten en cuatro direcciones Norte-Sur, Este-Oeste, Noreste-Sudoeste y Noroeste-Sudeste, su representación icónica se fundamenta en utilizar un color diferente para cada línea y emplear guiones para señalar las estaciones aisladas y círculos para aquellas estaciones donde se cruzan varias líneas. Los viajeros del metro pueden estudiar las posibilidades de conexión entre los dos puntos que delimitan una ruta, explorando las distintas líneas y transbordos, es decir, experimentando sobre el diagrama y obteniendo así una información específica adicional que no se plantearon los diseñadores del mapa en su construcción inicial. ${ }^{13}$ Pero no solo en los mapas se puede llevar a cabo este proceso de razonamiento diagramático en el que las relaciones implícitas se hacen explícitas. Como ya señalamos, en todos

11 «Una propiedad importante que permite distinguir un icono es que mediante su observación directa se pueden descubrir otras verdades referentes a su objeto, además de las necesarias para determinar su construcción». Peirce citado en Stjernfelt, F. Op. cit., p. 358.

12 «Todo razonamiento deductivo, incluso un silogismo sencillo, implica un elemento de observación; es decir, la deducción consiste en la construcción de un icono o diagrama de modo que la relación entre sus partes presente una completa analogía con las relaciones entre las partes del objeto de razonamiento, en experimentar con esta imagen en la imaginación, y en observar el resultado para descubrir relaciones ocultas o no identificadas previamente entre esas partes». Peirce citado en Ibid., p. 359

${ }_{13}$ Stjernfelt, F. «From diagrams to poetry: Peircean iconicity and diagrammaticalization strategies in Klaus Høeck's Poetry» en Iconic Investigations. Amsterdam, John Benjamins Publishing Co, 2013, p. 125. 
los iconos, en cualquier imagen o fotografía, sin darnos cuenta operamos del mismo modo realizando deducciones a partir de las estructuras relacionales que percibimos en ellos. El empleo de un marco - como el de una viñeta - genera un centro y una periferia, un entorno delimitado por una orientación en las cuatro direcciones espaciales que determina las relaciones entre un objeto representado y todos los demás y, al igual que en un mapa, adquiere significado gracias a ellas. ${ }^{14}$ Markus Arnold utiliza el cuadro La muerte de Marat de Jacques-Louis David para ilustrar este proceso de análisis diagramático, observando cómo el cuerpo de Marat se ubica en la región inferior del lienzo, alejándose de esa posición central de la que parece caer, y cómo el cuchillo con el que ha sido asesinado reposa en posición horizontal prácticamente en la misma línea en la que la pluma se mantiene todavía vertical en la mano de la víctima, lo que establece entre ellos una correspondencia, equiparándolos como armas y símbolos: la primera, de la violencia irracional, y la segunda, de la razón, otorgando además a esta última una posición victoriosa incluso después de la muerte de quien la esgrimía. La postura del cuerpo de Marat, con el brazo cayendo por su propio peso y la cabeza ladeada, compone un patrón que evoca a la Piedad de Miguel Ángel y asimilaría al revolucionario con la figura de Cristo. Con este análisis, Arnold refleja el proceso señalado por Peirce, en el que tras la inmediatez de esa primera impresión de una imagen se pasa a percibirla como un diagrama al detener la atención sobre ella, y las relaciones entre componentes que se detectan sirven, en un momento posterior, para elaborar proyecciones metafóricas - pluma y cuchillo como símbolos, la identificación de Marat con Cristo-, de las que obtenemos más información de la que aparentemente contenía el icono que sirvió de punto de partida. ${ }^{15}$

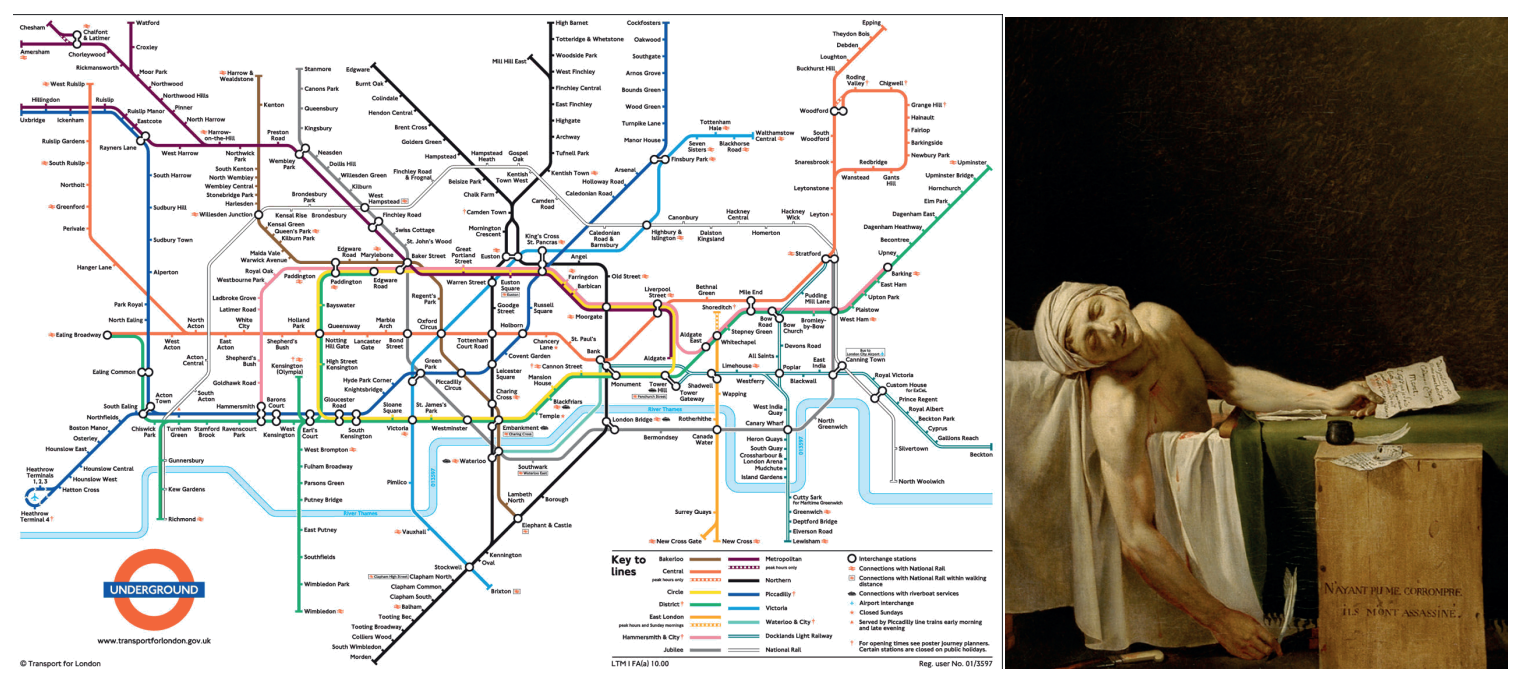

FIG. 2. El razonamiento diagramático se puede aplicar a un plano de metro y a una pintura.

${ }_{14}$ Arnold, M. «Images, diagrams, and narratives: Charles S. Peirce's epistemological theory of mental diagrams» en Semiotica 186-1/4. Berlín,Walter de Gruyter, 2011, pp. 5-20.

${ }^{15}$ Ibid., pp. 11-13. 

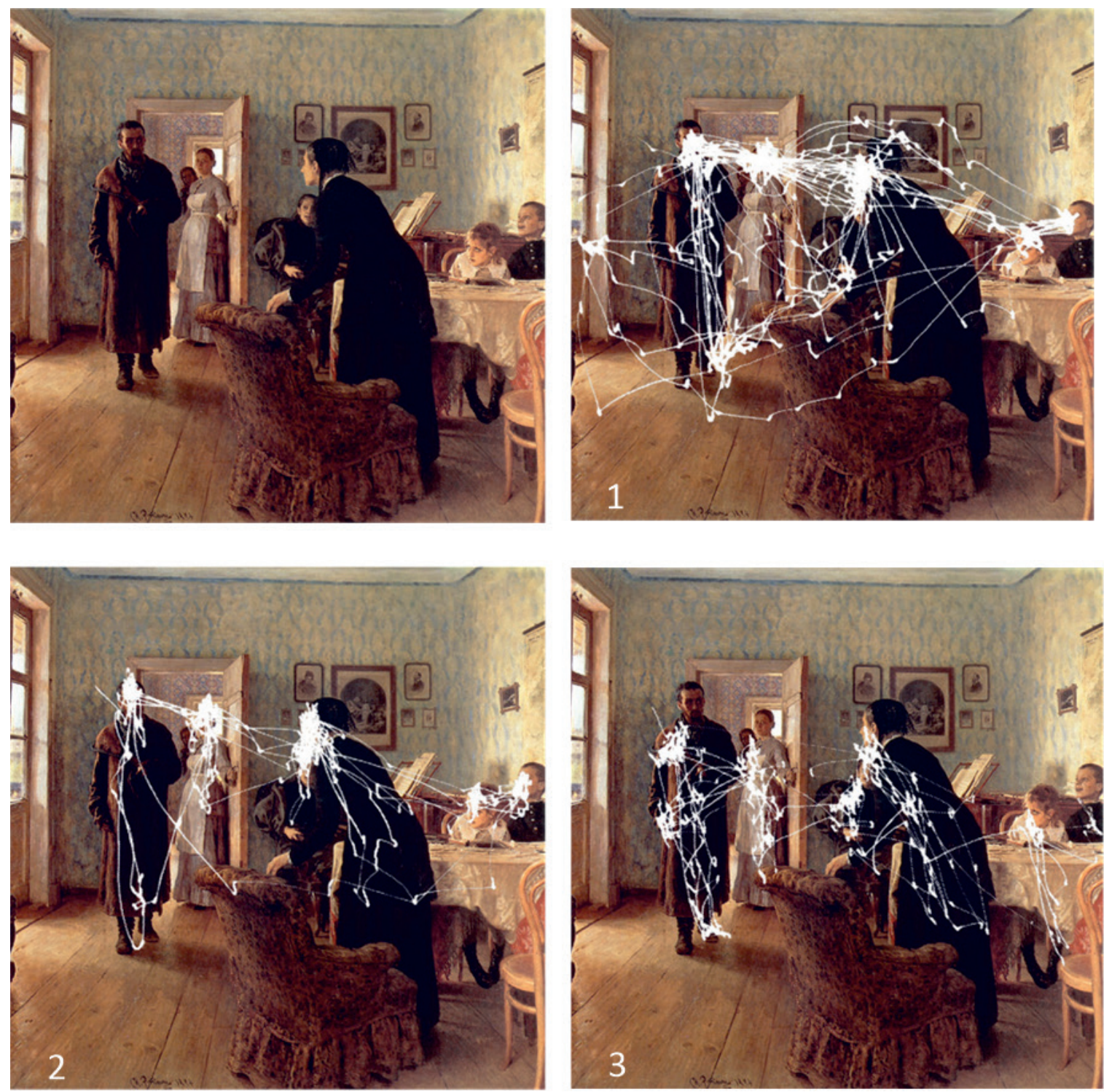

FIG. 3. Mapas de movimiento visual referenciados sobre la obra de Ilya Repin Un visitante inesperado (1884) de un sujeto al que se le pide: 1) observar la pintura libremente, 2) estimar la edad de los personajes, y 3) recordar la ropa que llevan puesta. Imágenes extraídas de la revista online Cabinet Magazine, n. ${ }^{\circ}$ 30, 2008. Disponible en http://www.cabinetmagazine.org/issues/30/ archibald.php

Esta exploración de la imagen en busca del diagrama parece quedar reflejada también en la trayectoria seguida por la mirada de su observador, como se puede apreciar en los resultados de los experimentos llevados a cabo por el psicólogo ruso Alfred L. Yarbus. En sus 
investigaciones, Yarbus registraba el recorrido de los movimientos sacádicos ${ }^{16}$ de un sujeto al que proponía examinar una imagen con un determinado propósito. Los resultados de algunos de estos experimentos se muestran en la FIG. 3.

Si consideramos la situación 2 en la que se proponía una estimación de edad de los personajes representados en la pintura, se aprecia cómo la mirada del observador se dirige a sus rostros pasando de unos a otros. Evaluando esos elementos aislados de la imagen global y estableciendo comparaciones entre ellos - a partir de la forma del rostro, sus arrugas, las canas en el cabello...- - se deducirán a nivel cognitivo una serie de relaciones que permitirán elaborar una hipotética escala de edades, una respuesta a la incógnita que servirá de punto de partida, y que se podrá representar en forma de diagrama, como el que se ofrece a continuación.

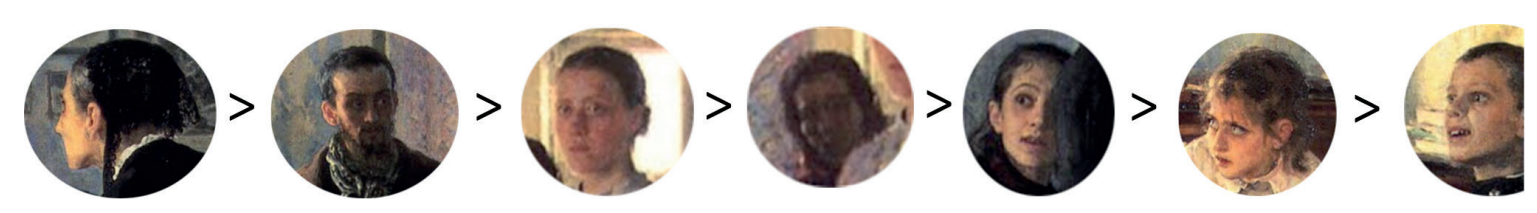

FIG. 4. Diagrama hipotético fruto del análisis de la obra Un visitante inesperado (1884) en la situación 2 .

El proceso de razonamiento diagramático descrito por Peirce se aplica también a esta situación, en la que a partir de un icono inicial se elabora un diagrama para obtener un conocimiento adicional, que no resultaba accesible directamente en esa inmediatez propia de la percepción directa de una imagen como hipoicono primario.

En su tesis doctoral en forma de cómic ${ }^{17}$ Nick Sousanis construye una magnífica página tomando como referencia la trayectoria de movimientos sacádicos registrados en un experimento de Yarbus, en el que el sujeto de prueba observaba la fotografía de un rostro femenino, y los traslada al semblante más célebre de la Gioconda. Empleando grupos de dos viñetas, Sousanis va dibujando en la superior el recorrido sacádico del observador y en la inferior la porción de imagen correspondiente sobre la que se estaría centrando su atención en ese preciso instante. Con esta representación pretende mostrar el modo en que el ser humano percibe las imágenes de forma fragmentaria y discontinua y cómo mediante la imaginación se construye un todo, completando la información de esos espacios intermedios vacíos. La elección de una ventana de exploración rectangular y la alusión a ese territorio en blanco

${ }_{16}$ El ojo humano está en constante movimiento, y a los desplazamientos conscientes que realizamos cuando dirigimos nuestra mirada a un punto concreto hay que añadir la ejecución de micromovimientos involuntarios de una duración del orden de los milisegundos, denominados movimientos sacádicos. El foco de nuestra mirada se va centrando en distintos puntos entre los que se desplaza a gran velocidad mediante estos movimientos sacádicos. Así se puede identificar sobre una determinada imagen una trayectoria de exploración visual que une esos puntos sobre los que se va fijando sucesivamente la atención del observador al realizar su «lectura».

17 Sousanis, N. Unflattening. Cambridge, Harvard University Press, 2015. 

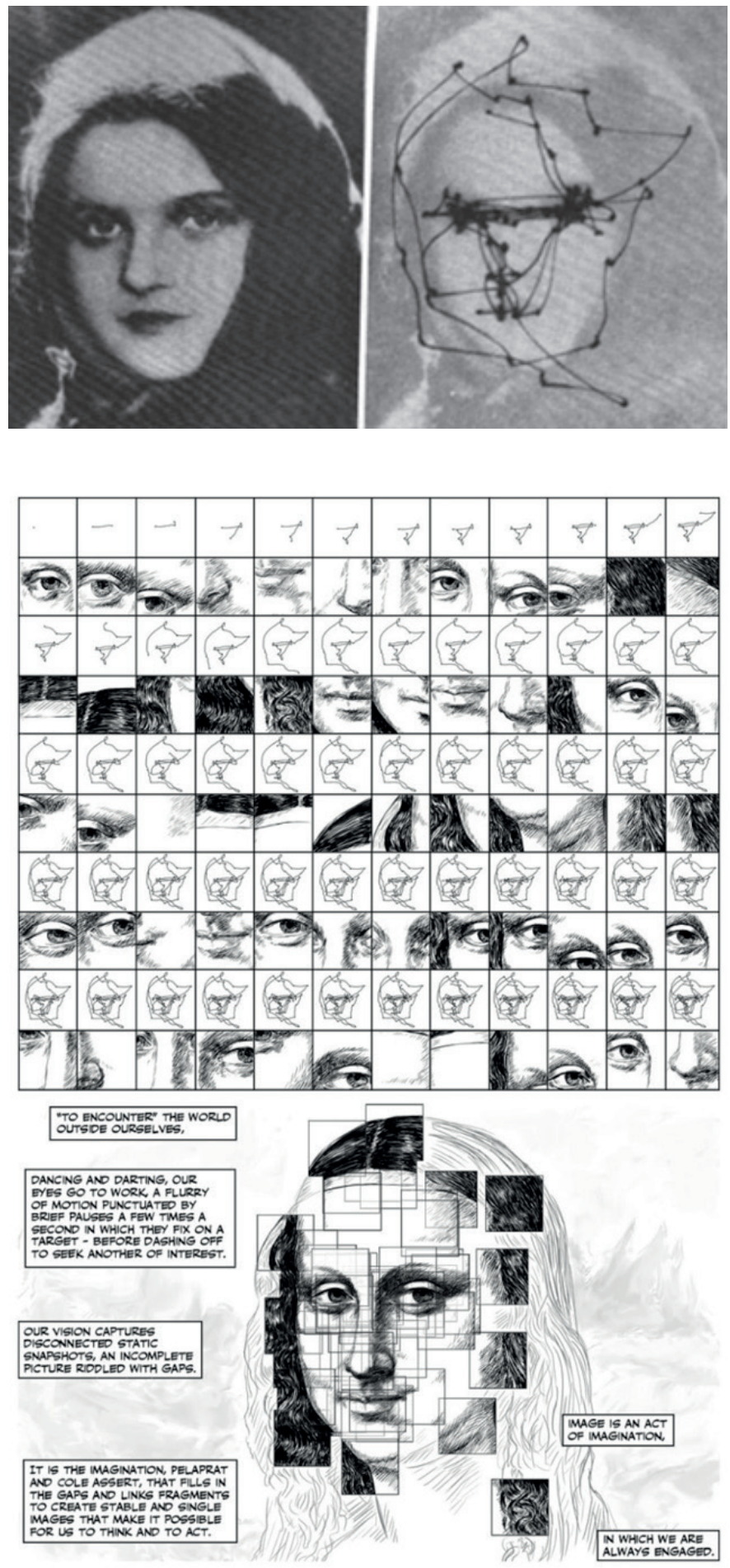

FIG. 5. (Arriba) Imagen de referencia y trayectoria de movimientos sacádicos. (Abajo) Unflattening (2015) de Nick Sousanis, p. 90. 
entre las imágenes discretas que percibimos resultan profundamente sugestivas: existiría un alto grado de coincidencia entre ese involuntario mecanismo de percepción visual y la forma que adopta el medio del cómic, con su despliegue espacial de viñetas separadas por calles que trazan surcos sobre la nada entre ellas.

En cualquier caso, más allá del poder de sugerencia de la página de Sousanis, podemos identificar de nuevo en ella las huellas de la teoría semiótica de Peirce. La trayectoria sacádica sobre un rostro humano opera como un análisis diagramático sobre un icono, buscando los principales elementos que lo forman y organizando un esquema básico, reconocible e interpretable del que, en función de su configuración, podremos extraer información adicional. Así, observamos cómo la capacidad cognitiva del ser humano opera de un modo similar a los sistemas de reconocimiento facial digitales, detectando ciertos puntos clave y comparándolos con patrones preestablecidos. $Y$ en esa caligrafía biológica se reconoce el fértil potencial significativo de una combinación mínima de elementos - apenas ojos y boca - demostrada con la incontestable proliferación del código desarrollado a partir de las posibilidades de diagramatización de una cara: los emoticonos. Esa lectura del diagrama en un rostro es la primera que realiza el ser humano y la más frecuente a lo largo de su vida. Aprenderemos a leer ojos y bocas, sonrisas y ceños fruncidos, antes incluso que a distinguir el icono de una gallina o un huevo - huevo o gallina, es independiente su orden, siempre resultarán posteriores - en un texto diseñado para facilitar el aprendizaje lector.
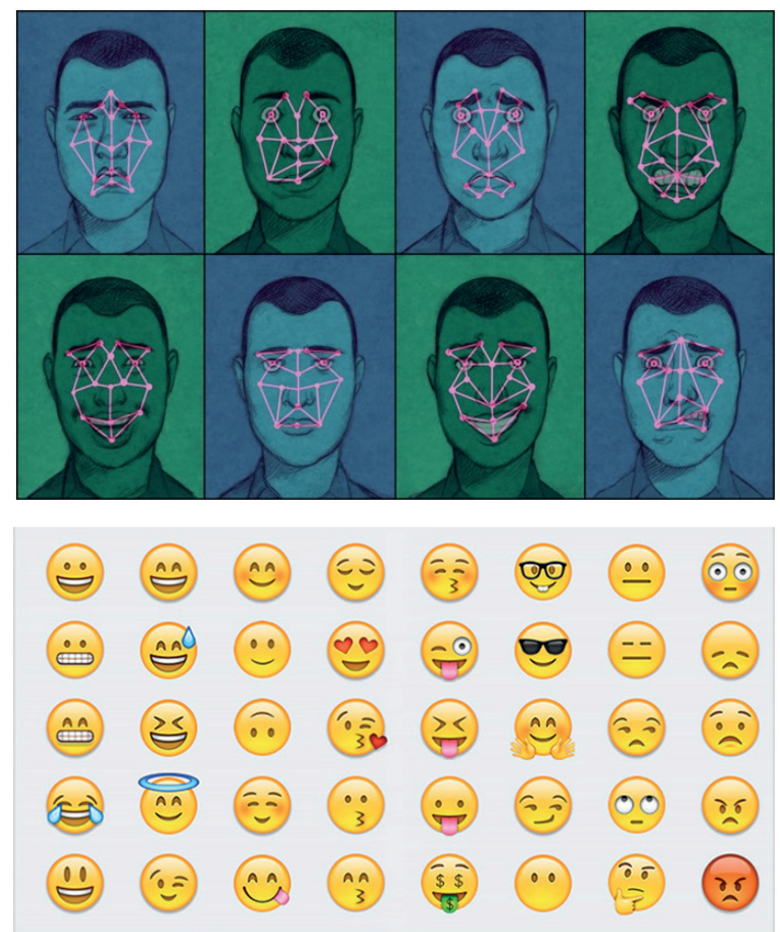

FIG. 6. (Arriba) Ilustración de Koren Shadmi para el New York Times Business con diagramas de puntos empleados en reconocimiento facial. (Abajo) Catálogo de emoticonos de WhatsApp. 


\section{Por una semiótica steampunk: un filósofo americano decimonónico vs. los teóricos del cómic de siglos venideros}

En los estudios que se acercan al cómic desde una perspectiva semiótica las ideas de Peirce no han llegado a encontrar un lugar destacable como herramienta de análisis. Más allá de esa limitada aproximación a la punta del iceberg de su taxonomía semiótica — sigh: iconos, índices y símbolos, solo tres entre sesenta y seis tipos distintos de categorías aplicables para definir los signos-, que no permite apreciar la extensión y elegancia del resto de su clasificación, no se han dado pasos significativos. La originalidad y profundidad de Peirce se han ido disipando en un eco cada vez más remoto de sus postulados iniciales, y en la semiótica del cómic apenas pervive el término icono, que a menudo parece insinuarse simplemente como sinónimo de imagen - sin ni siquiera tener en cuenta la subdivisión de la categoría del icono en imágenes, diagramas y metáforas-, y en otras ocasiones parece llegar a perder incluso cualquier connotación semiótica al identificarse directamente con el dibujo frente al que se colocan las instancias de lenguaje verbal en la historieta. Existen algunas notables excepciones a esta tendencia, como los artículos publicados por Magnussen, ${ }^{18}$ Manning ${ }^{19} \mathrm{o}$ Caldwell ${ }^{20}$ que comparten con este texto una misma intuición sobre el enorme potencial latente en las ideas de Peirce al ser trasladadas al ámbito de la teoría del cómic. Pero tampoco en estos casos se ha profundizado en el proceso de razonamiento diagramático que aquí consideramos algo clave.

Para equilibrar esa asimetría, podemos emprender un ejercicio lúdico de crítica steampunk. Un What if...? al estilo Marvel que explore otros mundos posibles. Imaginemos que un caballero victoriano de nombre Charles Sanders Peirce viajara a nuestra época en una máquina del tiempo impulsada a vapor y accidentalmente entrara en una tienda de cómics. Probablemente fascinado por el auge del medio, que en su tiempo apenas estaba emergiendo, adquiriría algún libro teórico — un ejemplar de Entender los cómics de Scott McCloud, por ejemplo- y algunos cómics que despertaran especialmente su curiosidad - Jimmy Corrigan, el chico más listo del mundo de Chris Ware y La Soga de Zer, entre otros-. Los leería con humildad. Sin esperar encontrar citas propias o referencias veladas a cada vuelta de página. Pero seguramente quedaría sorprendido al descubrir ciertas reinterpretaciones y algunas ausencias.

\section{¿Por qué lo llaman «icono» cuando quieren decir «diagrama»? Una relectura peirceana de Scott McCloud}

Procede en primer lugar reivindicar la obra de Scott McCloud como una de las más completas y accesibles aproximaciones teóricas al cómic, que no siempre encuentra un

\footnotetext{
${ }_{18}$ Magnussen, A. «The Semiotics of C. S. Peirce as a Theoretical Framework for the Understanding of Comics», en Magnussen, A. \& Christiansen, H. (eds.). Comics and Culture: Analytical and Theoretical Approaches to Comics. Copenhague, Museum Tusculanum, 2000, pp. 193-207.

19 Manning, A. D. «Review: Understanding Comics: The invisible Art» en Transactions on Professional Communication, Vol. 41, n.o 1 (1998), pp. 66-69.

${ }^{20}$ Caldwell, J. «Comic Panel Layout: A Peircean Analysis», en Studies in Comics, Vol. 2, n. ${ }^{2}$ (2012), pp. 317-338.
} 
reconocimiento apropiado en el mundo académico. La profundidad del estudio que se lleva a cabo en Entender el cómic puede parecer enmascarada por la amplitud de su vocación divulgativa. Pero su acercamiento se fundamenta sobre una base semiótica que, aunque adapte o prescinda de ciertos elementos, caracteriza el medio con una efectividad y una claridad encomiables.

Una de las tesis más interesantes de McCloud se centra en el reconocimiento de distintos grados de iconicidad de la representación pictórica que integran los cómics. Partiendo de un origen en el que se situaría una mímesis de estilo realista, la escala de iconicidad se aproximaría en una dirección hacia el plano puramente lingüístico y en otra hacia a un plano pictórico idealizado donde se ubicarían las cualidades fundamentales de la representación icónica. Tomando esas tres coordenadas - lo real, lo ideal pictórico y lo lingüístico- como vértices quedaría delimitada el área de un triángulo en cuyo interior se podría ubicar cualquier tipo de representación icónica, quedando caracterizada por su posición relativa respecto a estos tres puntos.

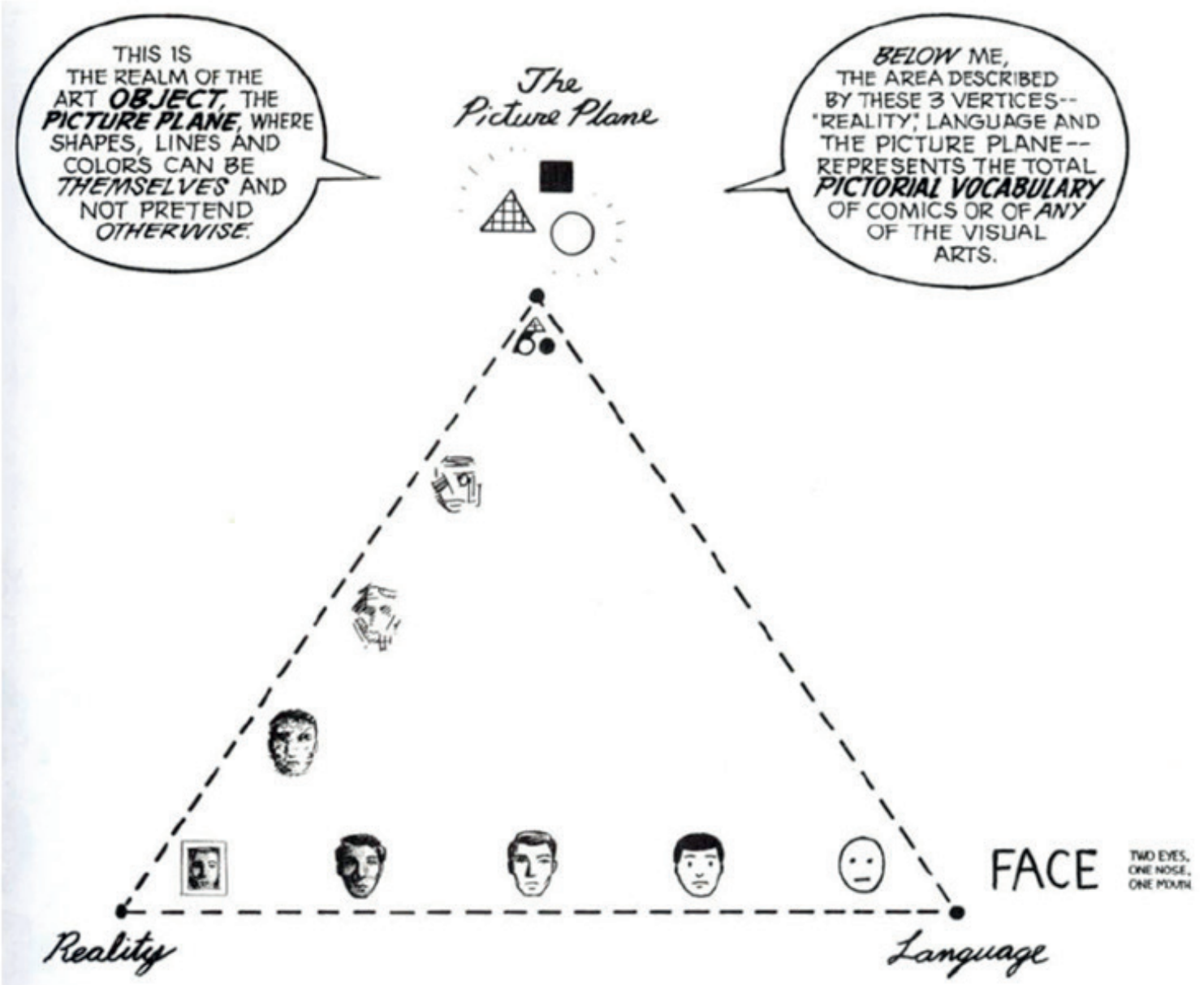

FIG. 7. El triángulo semiótico de McCloud.

Understanding Cómics, p. 51. 
En este esquema triangular, Alan D. Manning encontró una correspondencia exacta con una de las tipologías triádicas del signo definidas por Peirce. ${ }^{21} \mathrm{~A}$ los tres vértices que delimitan la representación de McCloud les superpone Manning tres clases de signo: el sinsigno, el legisigno y el qualisigno. En el plano pictórico ideal se ubicarían los cualisignos: esas cualidades abstractas que no pueden componer por ellas mismas un signo y que se realizan en otros signos materiales. Al plano de lo real quedarían asociados los sinsignos que se corresponden con representaciones tangibles, con eventos singulares o existentes individuales asociados a un tiempo y un espacio concretos, que no resultan repetibles y no están sistematizados. Y al plano lingüístico se vincularían aquellos a los que Peirce denominó legisignos, en los que su interpretación queda regulada por algún tipo de ley o norma que hace trascender la singularidad propia de los sinsignos, y que, debido a esa naturaleza general, hace posible su repetición en diferentes situaciones. ${ }^{22} \mathrm{Esa}$ progresiva gradación que establece $\mathrm{McCloud} \mathrm{para} \mathrm{permitir} \mathrm{situar} \mathrm{puntos} \mathrm{dentro} \mathrm{del} \mathrm{área}$ de este triángulo opera con la misma lógica semiótica que Peirce consideró en su aproximación a los signos, que ya indicamos al comentar la diferenciación entre índices, iconos y símbolos. De este modo en una determinada representación pictórica podremos detectar un distinto nivel de presencia de tres funciones semióticas distintas, cada una de ellas asociada en menor o mayor medida a las categorías idealizadas de cualisigno, sinsigno y legisigno respectivamente.

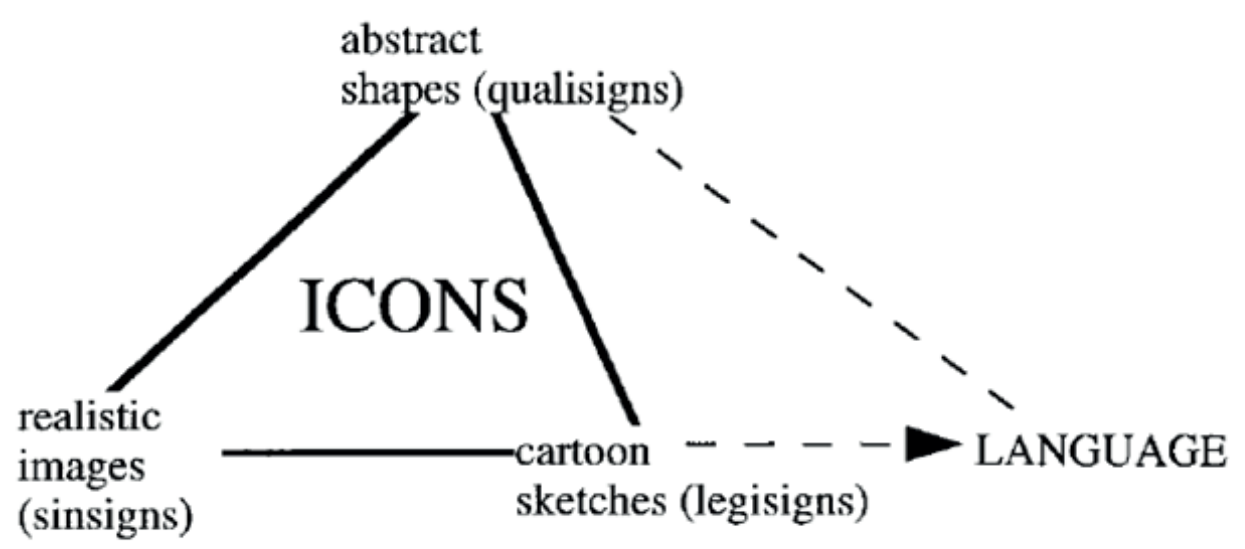

FIG. 8. Correspondencia de una de las triadas de Peirce con el triángulo de McCloud. Imagen tomada del artículo de Alan D. Manning.

Más allá de esta acertada coincidencia entre las teorías de McCloud y Peirce, una ligera matización terminológica puede servir para ampliar la comprensión del paralelismo. A esos iconos que en el vértice inferior derecho de su triángulo se aproximan a lo lingüístico por

${ }^{21}$ Manning, A. D. Op. cit., pp. 66-69.

22 Jappy, T. Introduction to Peircean Visual semiotics. Londres, Bloomsbury, 2013, pp. 30-31. 

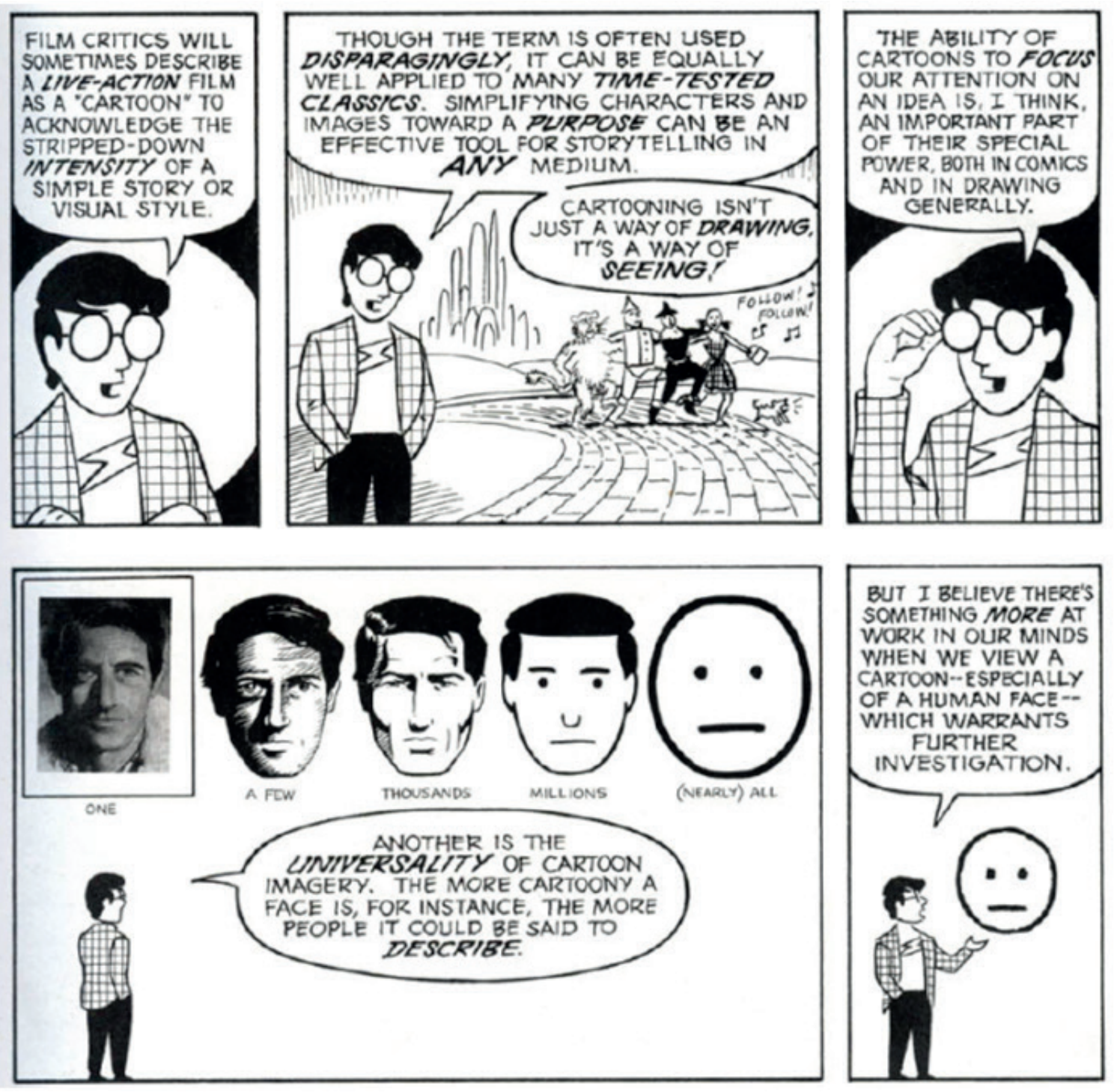

FIG. 9. McCloud, S. Understanding Cómics, p. 31.

su grado de abstracción, McCloud los identifica con los cartoons, con los dibujos propios del cómic, a los que asigna el grado máximo de iconicidad, atribuyendo a su simplicidad un mayor potencial de identificación del lector que facilitaría su inmersión y comprensión textuales. Cambiemos una palabra por otra: sustituyamos cartoon por «diagrama». Aprovechemos también para introducir la cita de un autor de cómic que sí empleó este último término en el sentido que aquí consideramos. En una entrevista en la que estaba comentando las diferencias entre el estilo sencillo de Chester Gould frente al realismo de Harold Foster o Alex Raymond, Art Spiegelman respondía así al ser preguntado por la diferencia entre el diagrama y la ilustración:

It's more important to know that the man is walking into the house than to see the five thousands fold concepts that make up that figure walking into the house [...]. At that point it's also important 
to understand what kind of house is he walking into, is he a tall man or a short man? These are the content parts of a picture that have to be diagrammed. ${ }^{23}$

Cuando en una viñeta McCloud afirma que «cartooning isn't just a way of drawing is a way of seeing $»^{24}$ (FIG. 9) podremos entonces interpretar en sus palabras que nuestra percepción visual a nivel cognitivo opera en parte gracias al reconocimiento de diagramas y a su manipulación mental. Cuando habla de la universalidad de ese tipo de representación sosteniendo que «the more cartoony a face is, for instance, the more people it could be said to describe ${ }^{25}$ (FIG. 9) podemos traducir en código peirceano que la reducción a lo diagramático aproxima a la generalidad propia de lo legisígnico.

De este modo, al comentar cómo cualquier ser humano reconoce su propio rostro en un enchufe, McCloud está aludiendo también al mismo fenómeno de razonamiento diagramático que propusiera Peirce. Cuando observamos un rostro llevamos a cabo un proceso de diagramatización mediante el que identificamos las relaciones fundamentales entre sus partes. Simplificando sus propiedades variables - las sombras que produce una iluminación concreta, las arrugas de la edad, una mayor o menor cantidad de pelo...- se va reduciendo el icono a sus propiedades básicas, a un diagrama en el que se mantiene la estructura esencial que permanece siempre constante en el rostro humano: esos dos puntos sobre una misma horizontal que representan los ojos, bajo los que ubicamos la línea de la boca. Al trasladar la forma de ese diagrama a otras representaciones podemos identificarla como su proyección metafórica y llegar a reconocer una cara en el frontal de un coche. Lo que para $\mathrm{McCloud} \mathrm{es} \mathrm{antropocentrismo,} \mathrm{Peirce} \mathrm{lo} \mathrm{trataría} \mathrm{como} \mathrm{poiesis} \mathrm{metafórica,} \mathrm{apli-}$ cable a cualquier signo.

Quizá sea conveniente subrayar que el reconocimiento de rostros es una de las primeras capacidades semióticas que desarrolla el ser humano durante su infancia más temprana, y resulta uno de los temas de investigación y experimentación más ampliamente estudiados en el campo de la psicología cognitiva. Se han llegado a realizar experimentos cuyos resultados parecen indicar que los recién nacidos poseerían un conocimiento innato de su estructura, debido a la preferencia que demuestran en el seguimiento visual de ciertos patrones — que adoptan el esquema básico de un diagrama facial - frente a otros — que presentan los componentes de este diagrama en configuraciones diferentes a la natural. ${ }^{26}$

\footnotetext{
23 «Es más importante entender que un hombre está entrando en una casa que apreciar los cinco mil pliegues que produce su figura al entrar en la casa [...] Llegados a ese punto es importante también apreciar en qué tipo de casa está entrando o si es un hombre alto o bajo. Estas son las partes de un dibujo que deben ser diagramadas». Spiegelman, A. Conversations. Jackson, University Press of Mississipi, 2007, pp. 285-286.

24 «Dibujar cartoons no es solo un estilo de dibujo, es un modo de mirar».

25 «Cuanto más cartoon es una cara, por ejemplo, un mayor número de individuos podrán identificarse en su representación».

${ }^{26}$ Morton, J. \& Johnson, M. H. «CONSPEC and CONLERN: A Two-Process Theory of Infant Face Recognition», en Psychological Review, vol. 98, n. ${ }^{\circ} 2$ (1991), pp. 164-181.
} 

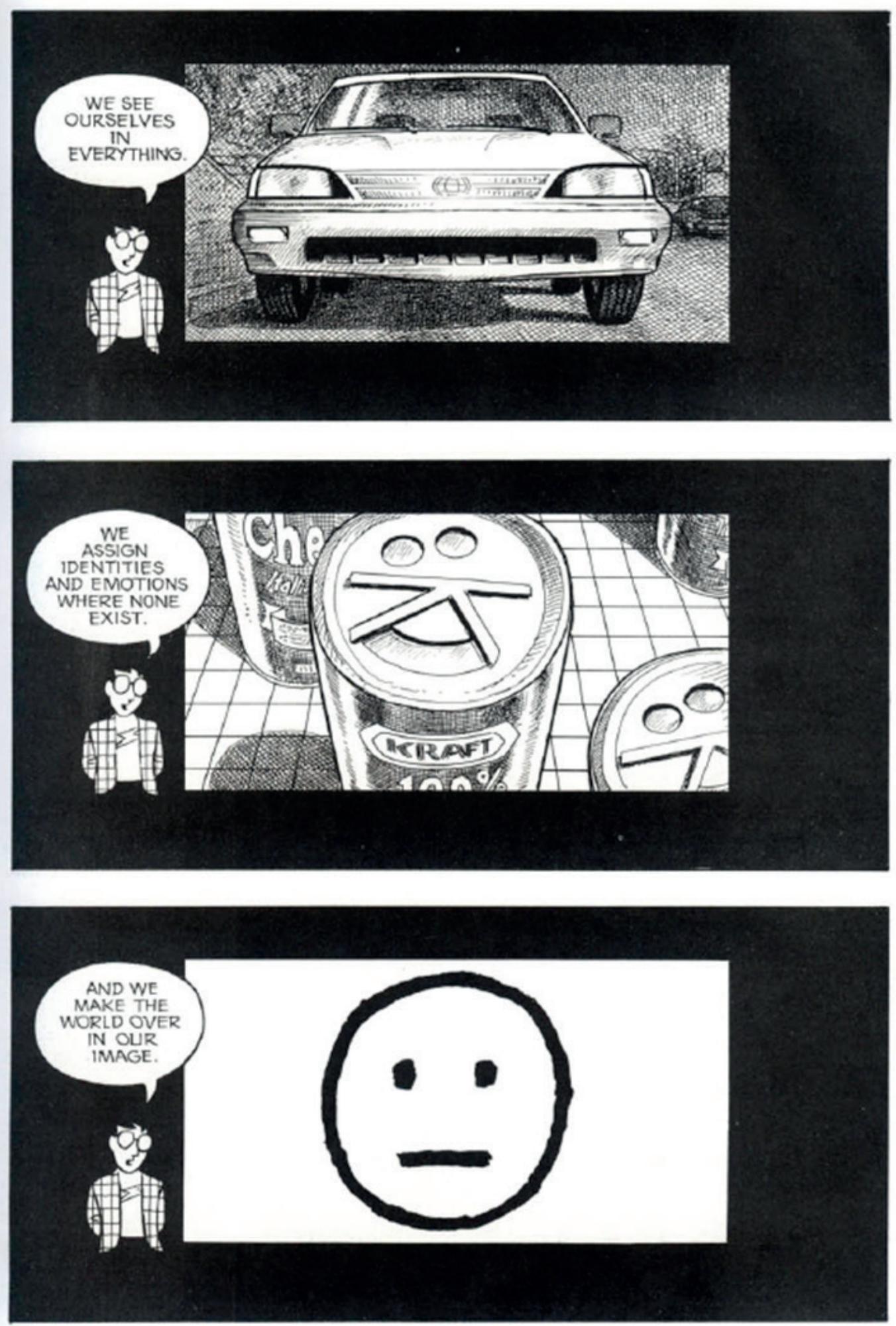

FIG. 10. Proyección metafórica de signos diagramáticos. McCloud, S. Understanding Comics, p. 33. 


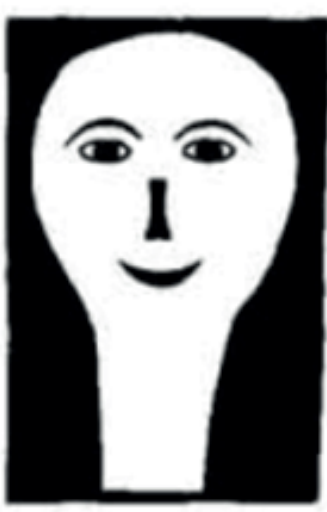

Face

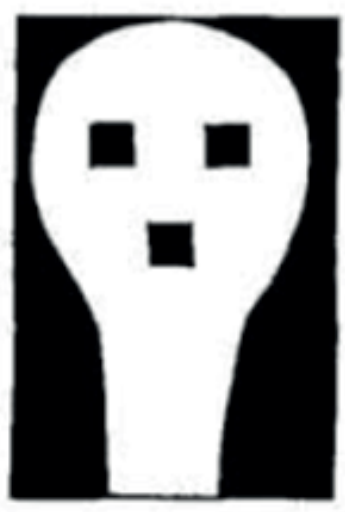

Config

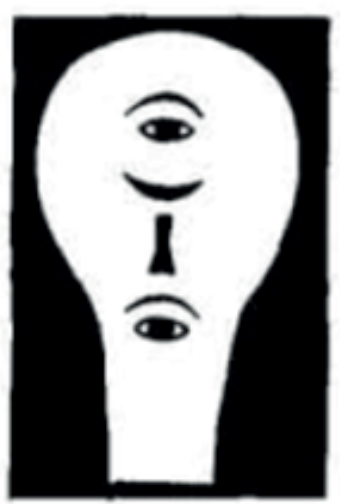

Linear

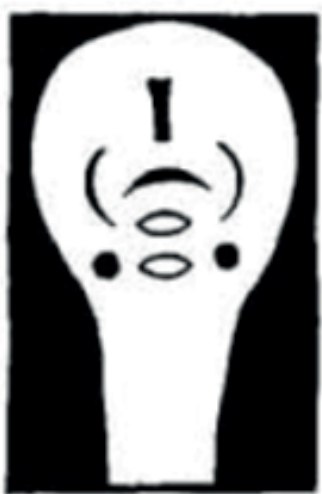

Scram

FIG. 11. Patrones faciales usados como estímulo de seguimiento en experimentos con recién nacidos.

\section{Cuando Peirce encontró a Ware}

Esa experiencia límite tan difícil de emular a la que hacía referencia Stjernfelt cuando comentaba la fase previa al análisis diagramático de un icono, en la que la inmediatez de la percepción permitía acceder a una imagen pura, a una sensación visual no mediada, podría ser entonces la que experimentara un bebé antes de reconocer por primera vez el rostro de su madre. $\mathrm{O}$ al menos, asumiendo esa idea como clave interpretativa, podemos proponer una lectura peirceana de la página de Chris Ware que se muestra a continuación.

Ware dedicó el número 20 de su ACME Novelty Library a representar la vida de un personaje, Jordan Wellington Lint, desde el momento de su nacimiento al instante de su muerte. En sus primeras páginas, el cómic adopta la perspectiva del protagonista cuando todavía es un bebé, poniendo en práctica un ejercicio de focalización interna que Roberto Bartual ha comparado con el estilo literario que adoptara Joyce en el comienzo de su Retrato del artista adolescente. ${ }^{27}$ Sin embargo, la retórica literaria no permite consumar una transposición efectiva en palabras de esa experiencia tan puramente visual del bebé recién nacido. Dudamos incluso de que otro medio visual como el cine lograra igualar la capacidad de representación que ofrece el cómic para adoptar la subjetividad en esta situación liminal, en la que el individuo se encuentra todavía en una etapa de su desarrollo cognitivo previa a la adquisición del lenguaje verbal (pero posterior a la del razonamiento diagramático). Detengámonos por un momento a considerar el proceso que Ware mimetiza y los recursos que emplea para ello.

${ }_{27}$ Bartual, R. «Inner focalization: a child's game», en The Comics Grid: Journal of Comics Scholarship, (2011). Disponible en http://blog.comicsgrid.com/2011/03/inner-focalization-a-childs-game-2/. 


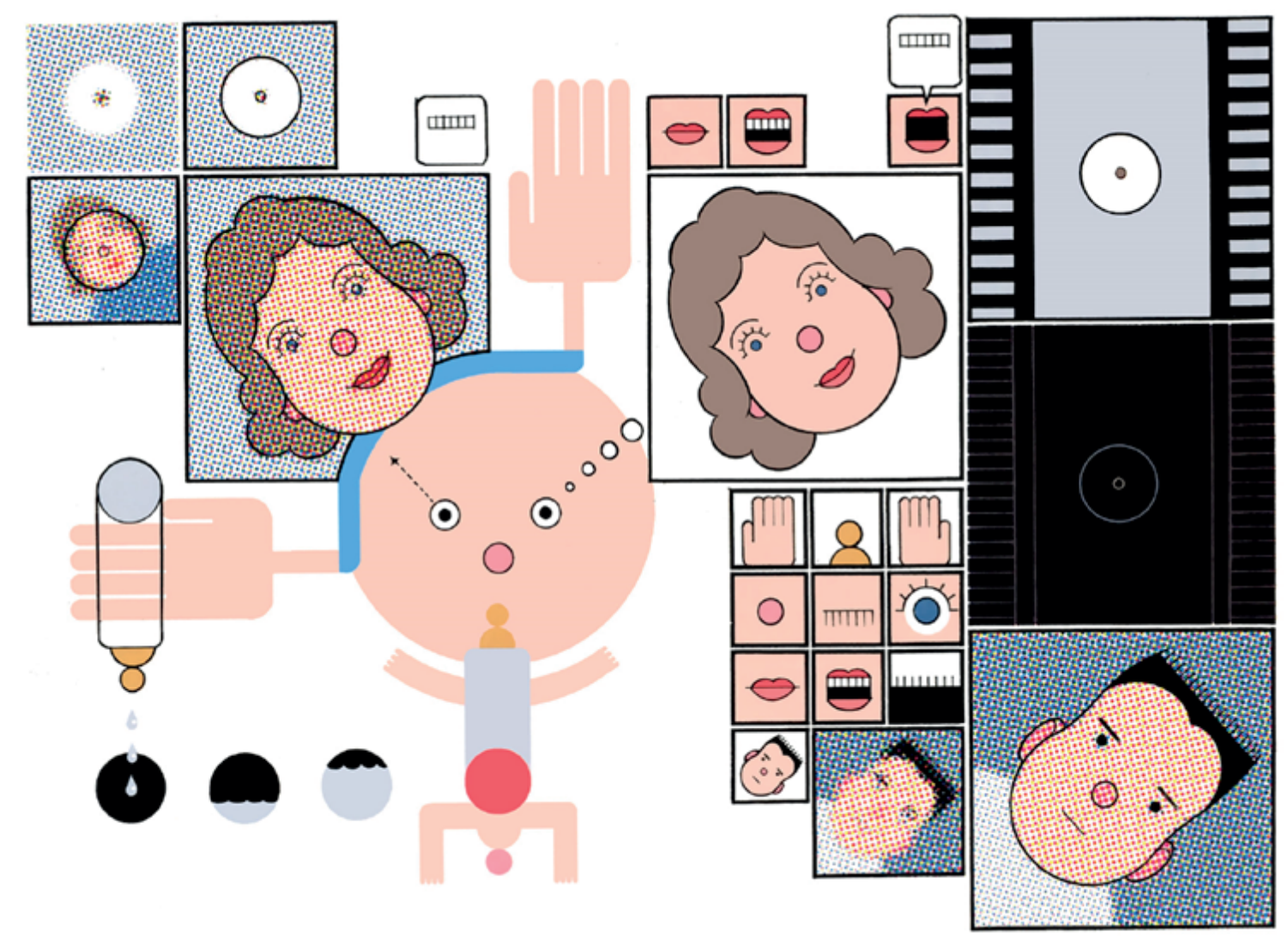

FIG.12.WARE, C. ACME Novelty Library, n. ${ }^{\circ}$ 20, p. 4.

Si intentamos seguir una secuencia de lectura lineal, en la entrada a la página (1) nos encontraremos una imagen difícilmente inteligible que presenta la textura de una impresión de semitonos en cuatricomía y carece del marco empleado normalmente para delimitar la viñeta. La experiencia que podría pretender traducir es la de esa percepción icónica primigenia del recién nacido - tan próxima a lo místico- en la que no existe individuación de elementos y el todo se advierte como una continuidad sin bordes ni distinciones. La elección de una técnica reprográfica elemental, que muestra las tramas superpuestas de semitonos de manera apreciable, y la ausencia de ese marco que en el medio del cómic ejerce de elemento singularizador y posibilita la secuencialidad entre viñetas independientes, operan como recursos metafóricos para simbolizar ese estado cognitivo primario, inconcebible desde la perspectiva de un adulto. Se intenta así acercar al lector a ese paraíso perdido, semióticamente inaccesible desde el momento en que comenzamos a desarrollar la capacidad de razonamiento diagramático sobre esa percepción icónica elemental. Y eso sucede en la siguiente viñeta (2). Sobre la misma imagen comienzan a mostrarse contornos que identifican distintos elementos: dos círculos parecen componer la forma de una lámpara encendida en la superficie uniforme del techo al que mira desde su cuna el bebé. Esta nueva capacidad cognitiva que permite dotar de individualidad a elementos dentro de un hipoicono primario, de elaborar un diagrama sobre una imagen percibida solo como tal, se subraya también 
con la aparición del marco de la viñeta. Esos contornos que acaban de hacer aparición se mantienen todavía cuando en la siguiente viñeta (3), que sigue representando el mismo punto de vista subjetivo del bebé, cambia el fondo de la imagen. Sobre la misma textura de semitonos en cuatricomía aparecen nuevas formas y colores todavía sin determinar, sin identidad propia. La lámpara permanece en la memoria a corto plazo del recién nacido hasta que vuelve a efectuar el proceso de diagramatización sobre la imagen para identificar sus nuevos elementos. Y en la cuarta viñeta (4), que supone una ampliación respecto al tamaño de las tres anteriores, se distingue, por fin, el rostro de la madre y aparecen delimitados por la línea de su contorno los componentes que lo definen: ojos, boca, nariz, orejas, pelo.

Una vez alcanzado ese punto, lo que parecía ser una secuencia de lectura relativamente convencional - cuatro viñetas que se suceden de izquierda a derecha y de filas superiores a inferiores, como indica la línea verde de la figura - se altera con la incorporación de un elemento central en la distribución de la página: la figura del propio bebé. Con su irrupción se trasmuta radicalmente la experiencia lectora y lo que constituía una secuencia temporal consecutiva se convierte en un diagrama que recoge una experiencia múltiple y simultánea. Y esta simultaneidad va más allá de esa otra, mencionada frecuentemente en los estudios teóricos de la historieta, que se refiere simplemente a la coexistencia espacial, en una misma página, de viñetas que corresponden a instantes distintos y sucesivos pero que el lector percibe al mismo tiempo si le dedica una primera mirada general. El fenómeno al que nos enfrentamos en la página de Ware tiene lugar en un nivel más profundo, que trasciende el propio de la recepción del discurso: acontece en el plano temporal de lo representado, no de la representación.

Las viñetas de la región izquierda de la página culminan su trayectoria lectora en el ojo izquierdo del bebé que las señala, con una flecha intermitente para indicar que se corresponde con sus percepciones visuales. Por otro lado, partiendo del ojo derecho del niño nos encontramos con esa cadena de burbujas que se utiliza convencionalmente para codificar el pensamiento de un personaje y que en este caso representaría una actividad cognitiva más básica: la identificación del rostro materno como esquema mental (5) —en una viñeta con el mismo tamaño que la imagen a su izquierda-, limpio de ese fondo ruidoso que provocan los semitonos, al ser abstraído cognitivamente de la continuidad analógica del ámbito perceptivo y trasladado a un proceso mental discreto, donde será interpretado como un diagrama. En esa representación se reconocen una serie de elementos que dan forma a su estructura y son mostrados individualmente en el grupo de viñetas inferior (6).

La disposición de la página, dividida en dos mitades simétricas sobre el eje vertical que separa los ojos del recién nacido, puede incluso llegar a sugerir una identificación de las funciones referidas con los hemisferios cerebrales sobre los que aparecen representadas: la percepción visual y auditiva con el hemisferio derecho y la abstracción cognitiva previa al proceso lingüístico con el izquierdo.

Existe otro conjunto de viñetas en la parte superior de la página que establece también un paralelismo perceptivo/cognitivo para representar la sensación auditiva del bebé. A la 


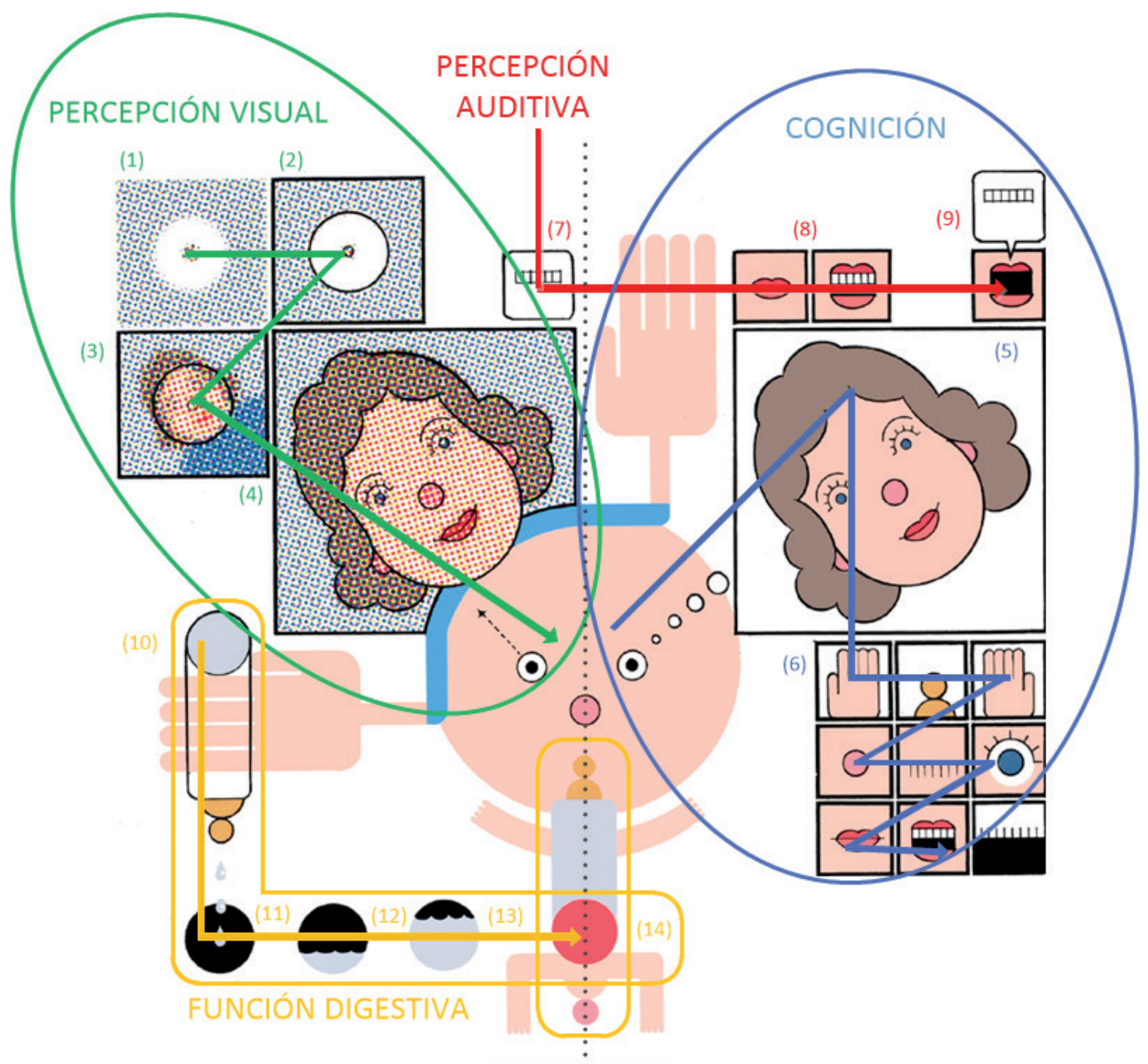

EJE CENTRAL

FIG. 13. Percepción diagramática del rostro materno y posibles secuencias visuales independientes de lectura. WARE, C. ACME Novelty Library, n. ${ }^{\circ} 20$, p. 4.

izquierda de ese eje central, que separa los dos ámbitos, se muestra una viñeta con un marco de bordes redondeados, diferentes a los que se han utilizado para las percepciones visuales, conteniendo una hilera de seis cuadrados consecutivos que sirven para metaforizar la primera impresión sonora que recibe el niño (7). En las viñetas equivalentes de la región mental derecha se muestra el proceso de localización de su origen en la boca de la madre. Para reproducir con su dibujo la carencia de significado de esos primeros sonidos escuchados, Ware acude a una metáfora sobre la que elabora una relación indexical. Esas seis casillas en blanco a la espera de ser rellenadas por un carácter, por un fonema que sumándose a otros les otorgue su condición simbólica, se asemejan a las celdas de un crucigrama vacío sobre las 
que se escribirá, letra a letra, la palabra asociada a una determinada definición. En este caso, las letras que componen el nombre propio del niño: J-O-R-D-A-N. El establecimiento de una relación que señale la procedencia del sonido representado se lleva a cabo gracias a la similitud formal entre esas casillas y los dientes de la madre. La coincidencia exacta en su ubicación dentro de la viñeta de la región cognitiva con la posición que ocupaban en la viñeta de la región perceptiva subraya la conexión semiótica (8). Tras un espacio en blanco, — que podríamos equiparar a la presencia de un símbolo «=», al tiempo de reflexión necesario para llegar a una conclusión - se muestra una conjunción de viñeta y bocadillo que explicita el éxito logrado en el proceso de asociación del sonido y su emisor (9). Sobre la viñeta que representa la boca abierta de la madre aparece un bocadillo que contiene las casillas en blanco, ese significante todavía hueco. El efecto que produce el conjunto es que esos dientes, que ahora no se muestran, se han trasladado directamente al contenido del bocadillo: el diente se habla, se torna letra en potencia, añadiendo una amplificación adicional a la relación indexical entre sonido y labios que ya implica el propio bocadillo. ${ }^{28}$

Entre los estímulos exteriores que recibe el bebé, y que se ubican en ese hemisferio izquierdo de la página, se representa también el proceso de su alimentación. Como herramienta de producción de significado, Ware recurre de nuevo a la definición de relaciones diagramáticas precisas entre un conjunto limitado de elementos. El vínculo que sirve para establecerlas es la identidad de una determinada cualidad formal - una correspondencia cualisígnica, podríamos decir-, que se comparte de forma exacta entre varios elementos situados en distintas posiciones sobre el espacio de la página. Una de estas coincidencias se detecta en la forma del biberón que sostiene la madre en su mano y el torso del recién nacido en el centro de la página. Es significativo que el cuerpo del niño resulte también simétrico en sentido vertical: la forma de la tetilla que se lleva a la boca es también idéntica, aunque con distinto color, a la de sus genitales — quedando así asimilado su tránsito digestivo a la simplicidad de un tubo-; lo que sirve para enfatizar lo limitado de las funciones fisiológicas del recién nacido en ese periodo. Pero más interesante que ese paralelismo resulta otro que se establece entre el círculo blanco, que sirve como base del biberón en la mano de la madre (10), y el círculo rojo, que sirve para indicar el aparato digestivo en el torso del bebé (14). La transferencia del líquido que contiene el biberón hacia el estómago del niño tiene lugar durante tres viñetas intermedias con la misma forma circular — quizá convenga reflexionar sobre el uso del término «viñeta» en este caso- en las que se muestra cómo el nivel de líquido va subiendo en su interior.

\section{La página del tiempo}

El especial desenvolvimiento del tiempo sobre la superficie de una página de cómic, al que ya hemos hecho referencia, es una de las particularidades sobre las que Scott McCloud llama la atención, enfatizando esa simultaneidad exclusiva de nuestro medio provocada por el despliegue de una línea de tiempo unidimensional sobre un espacio bidimensional.

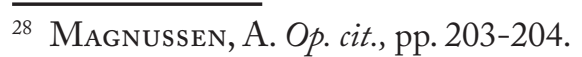




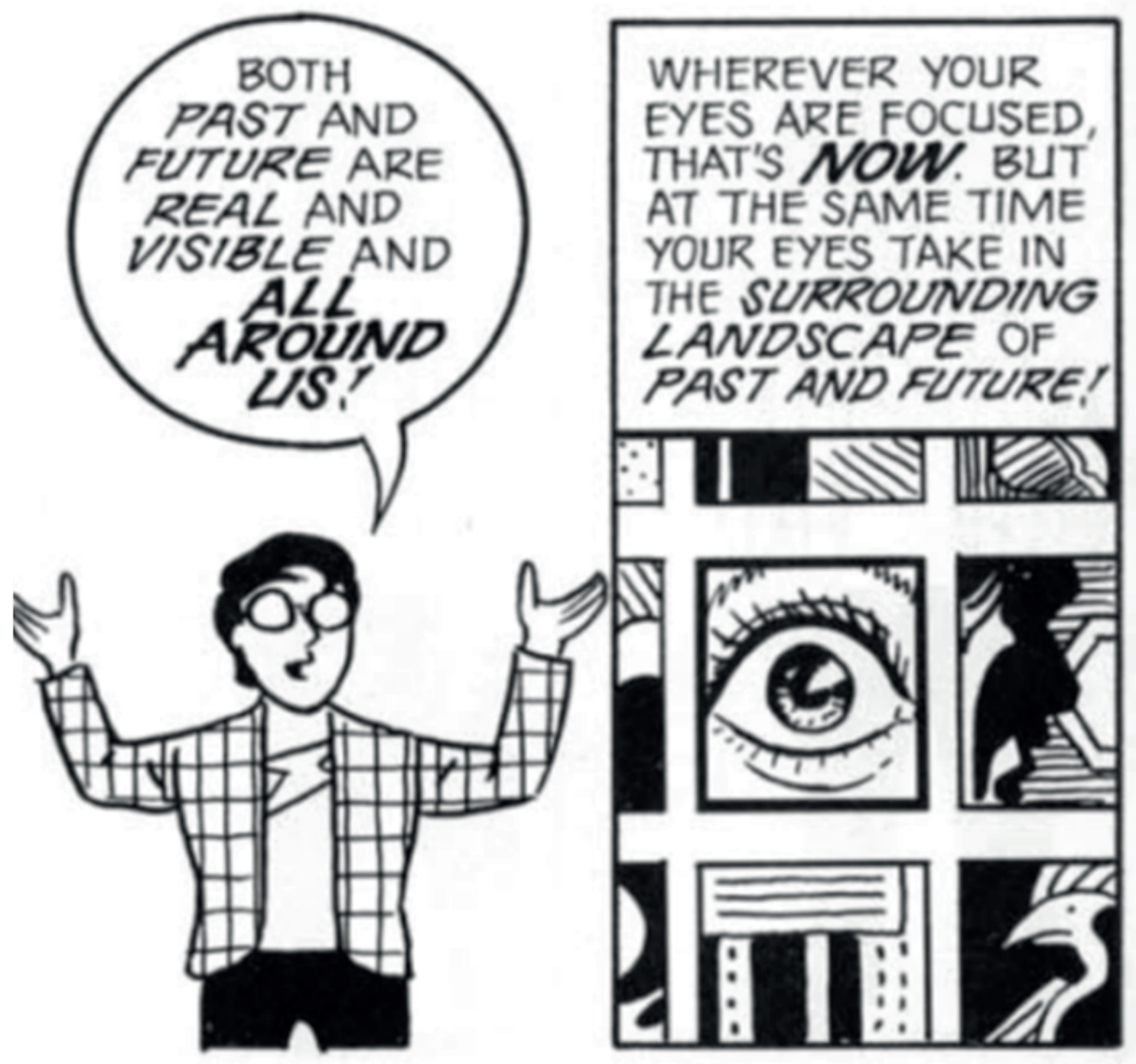

FIG. 14. McCloud, S. Understanding Comics, p. 104.

Es absolutamente cierto. El lector que observa una página de cómic puede percibir de un vistazo todo el tiempo que ella contiene: pasado, presente y futuro. Pero esa percepción se deshace tan pronto como se emprende el acto de lectura y con el gesto de mirar se va trazando, de viñeta en viñeta, una línea temporal de instantes sucesivos. Solo en ese momento previo en que la página se percibe como un hipoicono primario, como una imagen, se da la simultaneidad a la que se refiere $\mathrm{McCloud}$. Cuando en el proceso lector realizamos el escaneado de la página pasamos a entenderla como un diagrama de flujo básico en el que el tiempo se desenvuelve de forma secuencial. Esa linealidad ineludible, propia del tiempo de lectura, se impone también al tiempo representado en las viñetas de la página, incluso aunque no se llegue a alterar el orden cronológico en su secuencia o se alternen en ella escenas que pudieran estar teniendo lugar a la vez. 

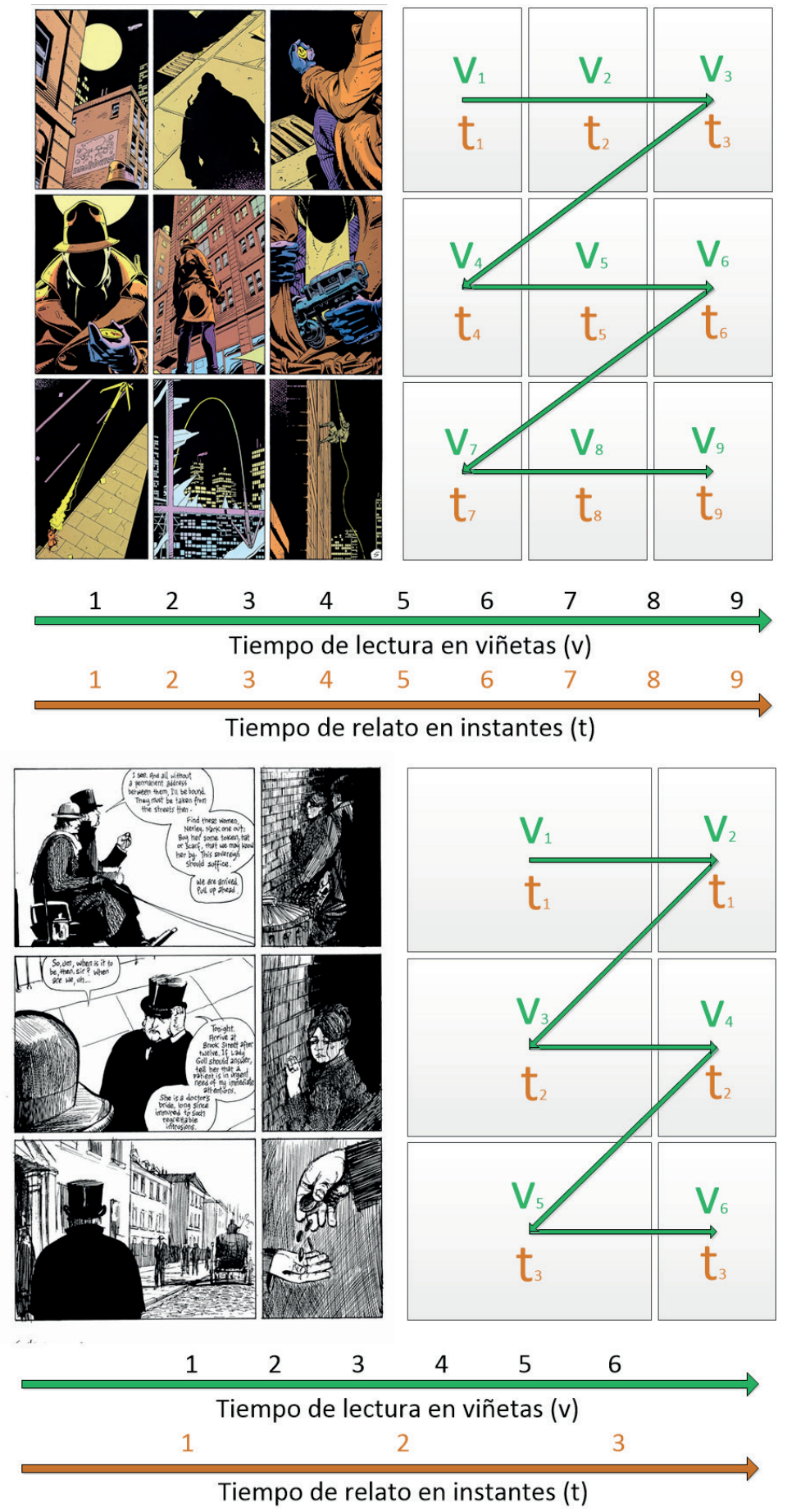

FIG. 15. Tiempos de lectura y relato en dos páginas de cómic. (Arriba) Página de Watchmen donde existe una sola trama. (Abajo) Página de From Hell donde se interpolan dos tramas simultáneas. En ambas la lectura sigue el patrón líneal en «Z» propio de composiciones de página sencillas. 
Sin embargo, si consideramos la página de Chris Ware nos enfrentamos a una situación distinta. El proceso de lectura lineal se rompe en el momento en el que nuestra atención se detiene en su elemento central: la figura del bebé. La relación que establece este elemento con los otros tres grupos de viñetas - los asociados a la percepción auditiva, el reconocimiento de elementos visuales aislados y la alimentación del recién nacido- no siguen la lógica de la sucesión temporal. Dentro de esos conjuntos de viñetas es posible identificar una secuencia temporal parcial - como en el caso de la progresiva transferencia del líquido del biberón al estómago del niño- pero como bloques independientes no adquieren un significado narrativo gracias a una relación de precedencia o sucesión frente a los otros grupos de viñetas, sino en su relación con esa figura central del bebé. $Y$ al contrario de lo que sucede en las secuencias narrativas de viñetas convencionales, la modificación del orden de lectura de cada una de estas secuencias no alteraría sustancialmente el significado de la representación global. Las categorías de presente, pasado y futuro pierden vigencia aquí y asistimos a una simultaneidad distinta a la que describe McCloud.

Esta alteración de la temporalidad ha sido reconocida previamente por Isaac Cates ${ }^{29}$ y Sergio Arredondo ${ }^{30}$ en sus estudios sobre el empleo de diagramas en el cómic y el potencial significativo que pueden aportar como recursos integrados en su lenguaje. Cates subraya el parentesco entre cómics y diagramas señalando cómo comparten una misma gramática, fundada sobre la yuxtaposición de imágenes y el establecimiento de relaciones en un espacio bidimensional para indicar conexiones significativas ${ }^{31}-\mathrm{y}$ en estas palabras de Cates una vez más se infiltra involuntariamente la definición de diagrama de Peirce-. Aunque en el caso del cómic predominaría siempre la intención narrativa, la consecución de una representación cronológica, también es posible encontrar préstamos diagramáticos de otro tipo donde la yuxtaposición gráfica representa relaciones ajenas a la secuenciación temporal. Por otra parte, Arredondo establece una tipología de diagramas introducidos en el discurso del cómic, identificando cuatro grandes familias: de estados, de estructuras y relaciones, para la visualización de datos y los que desarrollan una secuencia temporal.

La página de Ware que estamos considerando encajaría dentro de la familia de esquemas que Arredondo define como «diagrama de estructuras y relaciones», caracterizados por el empleo de vectores de conexión para establecer relaciones convergentes o divergentes - esas flechas que salen de los ojos del niño, las manos de la madre realizando una función similar- y en los que se pueden encontrar también desarrollos híbridos que incorporen algún tipo de evolución temporal, como es el caso. La aproximación teórica de Arredondo resulta iluminadora en muchos aspectos y todavía más al ser contrastada con su puesta en práctica, compaginando su lectura con la del excepcional cómic La Soga, también de su autoría. Pero el énfasis con el que subraya la condición de los diagramas

${ }^{29}$ Cates, I. «Comics and the Grammar of Diagrams», en Ball, D. M. \& Kuhlman, M. B. (eds.). The Comics of Chris Ware. Drawing is a way of thinking. Jackson, University Press of Mississipi, 2010, pp. 90-102.

30 Arredondo, S. «Las formas esquemáticas como contenido del cómic en la obra de Kevin Huizenga y Dan Zettwoch», en CuCo, Cuadernos de cómic, n. 3 (2014), pp. 7-23.

31 Cates, I. Op. cit., p. 95. 
como contenido dentro del continente global que supondría una historieta — también insinuada por Cates- puede matizarse aventurando una hipótesis que en cierto modo subvierte esa idea.

Retomando el análisis de la página de Ware podemos considerar que su composición se regiría por una macroestructura diagramática de orden superior sobre la que se incorporarían, en los distintos bloques señalados previamente, otras microestructuras que adoptan la codificación propia del lenguaje del cómic. Si esta página se ofreciera de forma independiente, sin estar integrada dentro de una obra completa, podríamos afirmar que, en ese caso, sería el diagrama el que contendría al cómic y no a la inversa.

Es cierto que la página que venimos comentando forma parte de un cómic que la contendría y dentro del que se integraría de forma natural; el recurso al diagrama puede llamar la atención y podría afirmarse que dilata las posibilidades de los componentes tradicionales de su código, pero en ningún caso supone una ruptura o una intromisión absolutamente ajena que transforme la historieta en otra cosa. Podríamos apelar aquí a esa inagotable capacidad de incorporación icónica, que se mencionaba al comienzo de este texto, pero vamos a aventurar una premisa distinta, que estreche todavía más esos lazos de parentesco que reconocían Cates y Arredondo, y quizás permita abrir nuevas vías de aproximación semiótica a la teoría del cómic.

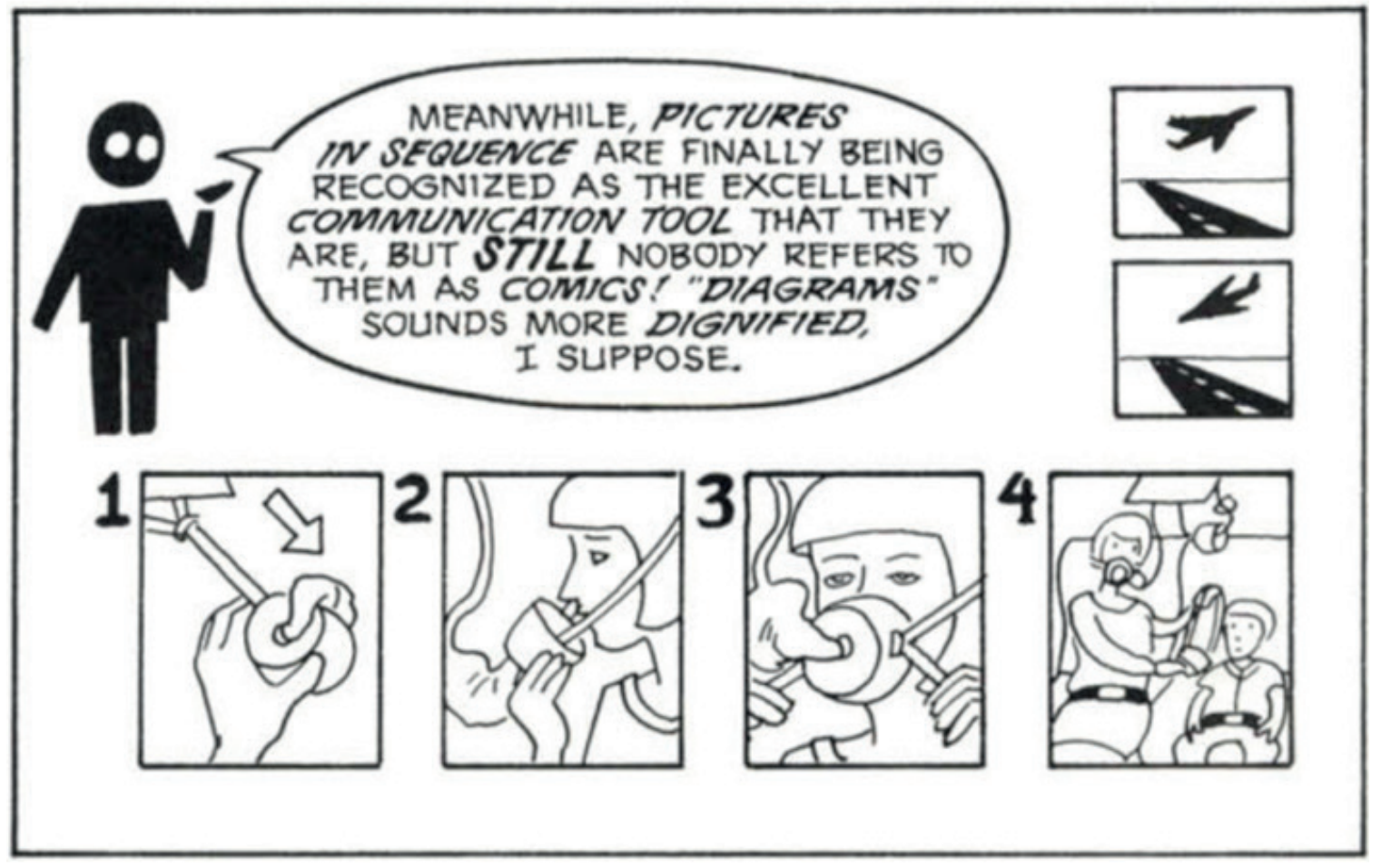

FIG. 16. Según McCloud los diagramas son cómics. McCloud, S. Understanding Cómics, p. 20. 


\section{Diagrama de diagramas, acercarse al cómic caminando de espaldas. $\mathrm{O}$, quizás: un dia- grama para integrarlos a todos}

En esas páginas iniciales de Entender el cómic, en las que McCloud concentra una historia detallada de los antecedentes del medio, habla también del potencial de las secuencias de imágenes para transmitir instrucciones informativas. Su comentario insinúa la condición historietística de esas manifestaciones, que intentaría enmascararse identificándolas mediante un término supuestamente más prestigioso: «diagramas». Con esa afirmación se pretende dar a entender que los diagramas, en el fondo, son cómics. No llevaremos aquí la contraria a McCloud, pero sí invertiremos la relación entre los términos de esa igualdad para sostener que los cómics, en el fondo, son diagramas.

Esa misma sospecha de circularidad, de sinonimia agazapada, que se observa en las palabras de McCloud se intuye también en la cita de Alan Moore que abre este texto. Al afirmar que ciertos experimentos programados por el Pentágono demostrarían que los cómics ofrecen una mayor potencia comunicativa que otras posibles combinaciones de imágenes y lenguaje escrito, parece que Moore en lugar de a un cómic de Spiderman se está refiriendo a lo que entendemos generalmente por diagramas enfocados a la transmisión eficaz de información ${ }^{32}$ — que McCloud ilustra con el ejemplo por excelencia: las instrucciones de seguridad en un avión-. Pero lo destacable en ambos casos resulta la identidad semántica entre cómic y diagrama.

Al igual que McCloud y Moore, creemos que la estructura fundamental del cómic, con su sucesión de viñetas consecutivas, puede asimilarse al tipo de diagramas que Arredondo relaciona con los desarrollos temporales y de los que él mismo ya subraya «la proximidad de estas formas esquemáticas al propio sistema del cómic. ${ }^{33}$ Podemos considerar cada viñeta como un elemento del diagrama, que aislaría un determinado evento de la narración mediante el empleo de un marco. La secuencia de viñetas establece conexiones entre estos eventos, que se van enlazando unos con otros, dejando entre sí espacios en blanco donde puede intuirse la ausencia de una indicación vectorial - una flecha del tiempo que trazaría ese patrón estándar de lectura en «Z» que queda implícita-. La representación de los sucesos contenidos en las viñetas se lleva a cabo combinando imágenes y lenguaje verbal, pero si en esos recuadros encontráramos únicamente un comentario escrito, la condición diagramática quedaría explicitada de forma incontrovertible: podríamos decir entonces que nos enfrentamos a un diagrama narrativo que reflejaría la trama de un determinado relato.

$\mathrm{Al}$ identificar así el cómic con una manifestación diagramática no pretendemos instalar un reduccionismo que soslaye la complejidad y riqueza del código semiótico que le es propio

32 En el texto completo que recoge la cita de Moore que hemos extraído aquí se extiende la argumentación al terreno de las ciencias cognitivas, atribuyendo esa efectividad semiótica del cómic a la operación simultánea de funciones propias de la actividad verbal con funciones preverbales (actividad visual relacionada con la facultad imaginativa) que facilitan el empleo de la memoria, ya que está demostrado que retenemos con más efectividad imágenes que palabras.

33 Arredondo, S. Op. cit., p. 13. 


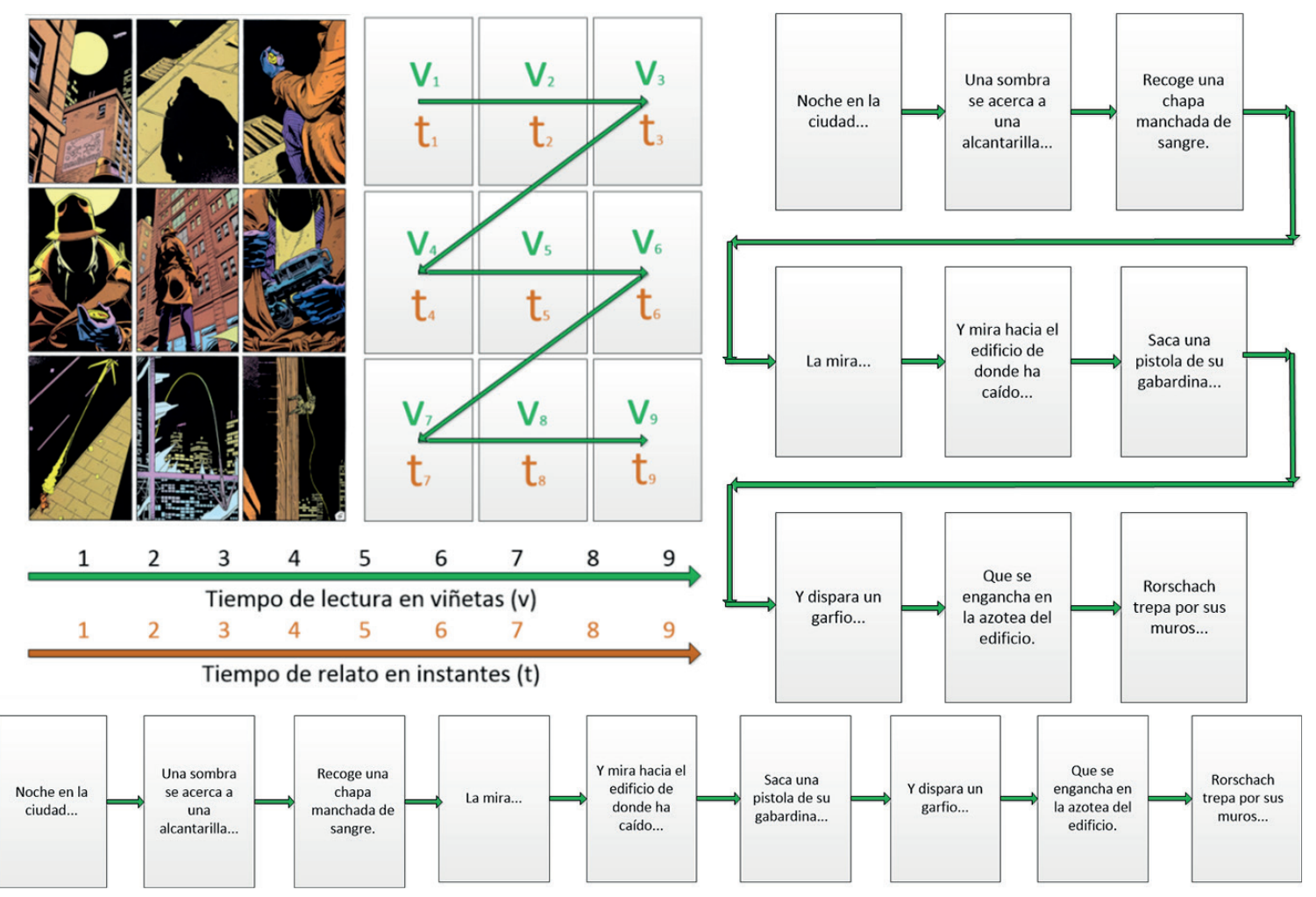

FIG. 17. Sustitución de imágenes en viñetas para explicitar la condición diagramática del cómic y su especificidad cronológica.

ni fomentar el menosprecio que pueda parecer implicar su consideración como forma integrada dentro de una categoría de orden más general. Al contrario, creemos que el estudio desde esta perspectiva puede enriquecer las aproximaciones teóricas en ambos campos y ampliar de manera ilimitada las posibilidades poéticas del medio. El cómic resultaría así un diagrama de diagramas donde encontraría cabida cualquier expresión semiótica multimodal en la que convivieran imágenes y lenguaje verbal. Al contrario que con la literatura, en la que cualquier intromisión ajena a lo textual altera sustancialmente el medio, como observábamos al principio de este texto, en esa página dedicada al aprendizaje lector en la infancia, no existiría elemento ajeno al cómic y toda incorporación resultaría enriquecedora.

Y en ese camino que se abriría dentro de la teoría semiótica del cómic, igual que Virgilio acompañó a Dante en su periplo desde el Infierno al Cielo, solo es posible considerar un guía. Una figura a reivindicar y a redescubrir, a rescatar del olvido impuesto por aquellos que lo situaron en oposición a Saussure y después eligieron a este último sin mirar jamás al otro lado. Porque si Charles Sander Peirce entrara hoy en una tienda de cómics saldría de ella conteniendo una sonrisa triunfante mientras consideraba las innumerables posibilidades que se desplegaban frente a él, en un prometedor horizonte hacia el que avanzaría repitiendo para sus adentros: «Stay tuned for more rock and roll». 


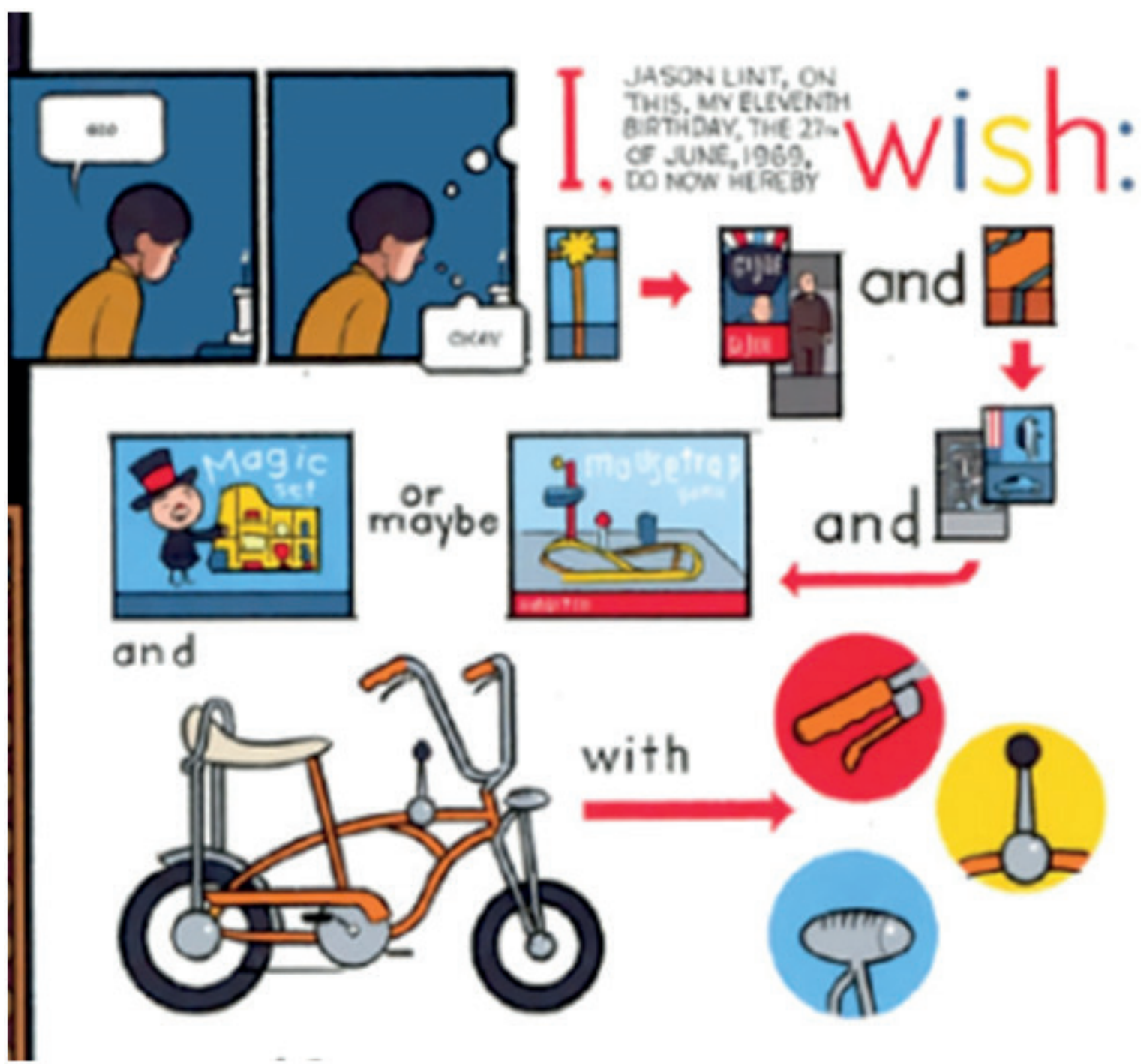

FIG.18. Diagrama que representa el pensamiento de un niño, sustituyendo en la composición sintagmática imágenes por palabras y siguiendo una trayectoria de lectura anómala indicada mediante flechas. WARE, C. ACME Novelty Library, n. ${ }^{\circ} 20$, p. 15. 